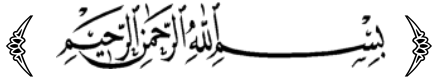

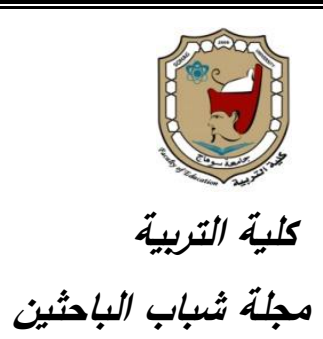

فاعلية بينة تملم افتراضية قاتمة على النظرية البنائية الابتماعية في تدريس العثوم على ثنمية الافاهيم العلمية والهس العلمي لدى تلاميذ الصف الثاني الإعدادي

( بجثمشتق من مسالةعلمية تخصص المناهجوطرقتدرس)

$$
\text { إعداد }
$$

أ أد/ برية محمد محمد حسانين أ.د / حسام الدين محمد مازن أستاذ المناهج وطرق تلدريس أستاذ المناهج وتكنولوجيا تعليم العلوم العلوم

كلية التربية - جامعة سوهاج كلية التربية - جامعة سوهاج

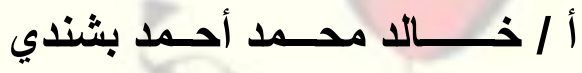
باحث دكتوراه - قسم المناهج وطرق تدريس

DOI :10.21608/JYSE.2020.

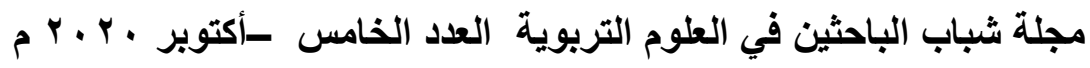
Print:(ISSN 2682-2989) Online:(ISSN 2682-2997) 
ملخص

عنوان البحث: "فاعلية بيئة تعلم افتراضية قائمة على النظرية البنائية الاجتماعية في تدريس العلوم على تنمية المفاهيم العلمية والحس العلمي لاى تلاميذ الصف الثاني

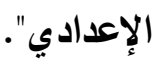

وتحددت مشكلة البحث الحالي في ضعف مستوى تحصيل تلاميذ الصف الثاني الإعدادي للمفاهيم العلمية في مادة العلوم، والحس العلمي لايهم، وذلك نتيجة استراتيجيات التدريس التي يستخدمها المعلم في تدريس العلوم للتلاميذ. واستهـف البحث الحالي تنمية المفاهيم العلمية والحس العلمي في مادة العلوم لاي تلاميذ الصف الثاني الإعدادي عينة البحث. وقد تم استخدام المنهج شبه التجريبي ذي المجموعتين المتكافئتين التجريبية والضابطة مع وجود قياس قبلي ويعدى لاختبار المفاهيم العلمية ومقياس الحس العلمي.

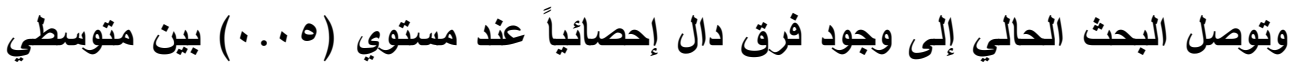
درجات تلاميذ المجموعة التجريبية التي درست وحدة "الصوت والضوء "باستخدام بيئة التعلم الافتراضية القائمة على نموذج "سوشمان" للأحداث المتناقضة، والمجموعة الضابطة التي درديات درست نفس الوحدة بالطريقة المعتادة في التطبيق البعدي لكلِ من اختبار المفاهيم العلمية، ومقياس الحس العلمي لصالح المجموعة التجريبية. وفى ضوء هذه النتائج يوصى الباحث بضرورة استخدام بيئة التعلم الافتراضية القائمة على نموذج "سوشمان" للأحداث المتناقضة فى تدريس العلوم، وذلك لتحسين المخرجات التعليمية ، وتحقيق الأهداف التعليمية، كما يوصى الباحث بضرورة التأكيا على تدريب المعلمين على كيفية استخدامه في التدريس، وإجراء المزيد من الدراسات في هذه الطريقة. الكلمات المفتاحية : بيئة تعلم افتراضية- النظرية البنائية الاجتماعية- نموذج "سوشئمانية للأحداث المتناقضة- المفاهيم العلمية- الحس العلمي . 
مقدمة:

تتجه دول العالم جاهدة إلى الاهتمام بمهارات التفكير حتى تستطيع مواجهة تحديات ومستجدات العصر الحالي بما يتميز به من تغيرات متلاحقة ناجمة عن التطور التقتي السريع

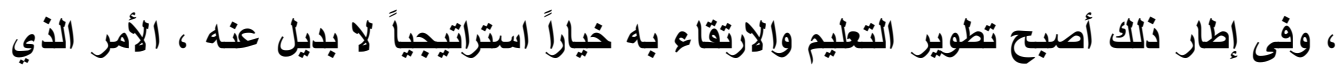

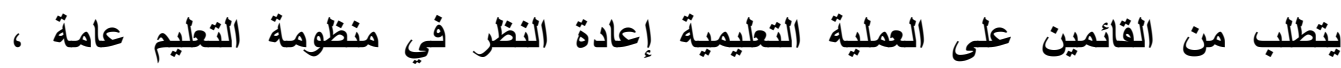
والممارسات التربوية خاصة بما يتيح للمتعلم الاستفادة من المستحدثات التكنولوجية فى تنمية قدراته التحصيلية وإلمهارية. وتُعد مادة العلوم من أكثر المواد الدراسية حاجة الى توظيف المستحدثات التكنولوجية في تعليمها، حيث أن الطرق والوسائل التقليدية المستخدمة لم تُعد قادرة على مواكبة التحديات

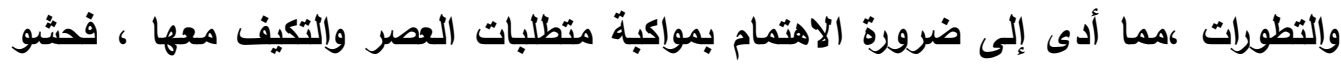
عقول الطلاب بالمعلومات لم تُعد مفيدة ، بل الأهم تعلم المتعلمين كيف يستخدمون ويوظفون

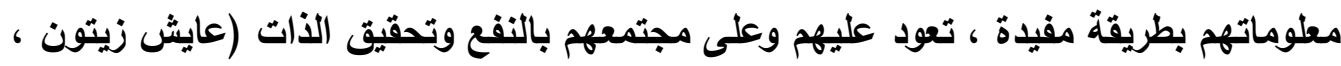
. (r) 9 6 r... V كما يشهر العالم تقدماً كبيراً في تطور المعارف والعلوم نتيجة سرعة انتشار استخدام شبكة الإنترنت وتطبيقاتها في شتى المجالات السياسية والاقتصادية والتربوية، مما دفع الكثير من المجتمعات إلى تغييرات ملموسة في مخططات تعليمها حيث أصبح المتعلّم قادراً على الحصول على المعلومات التي يحتاجها في أسرع وقت ويأقل مجهود.

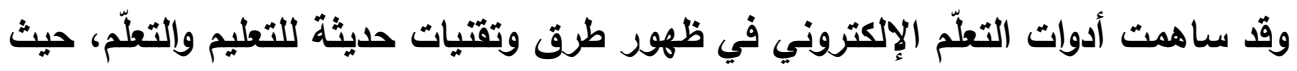
ظهر ما يسمى بالصفوف الافتراضية والواقع الافتراضي والمكتبة الافتراضية، فهذا التطور في ولئي مجال التعليم جاء نتيجة الثورة المعلوماتية وتطور وسائل الاتصال، فالصف الافتراضي عنصر

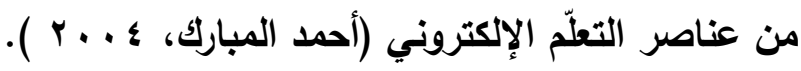
ويستخدم بعض الباحثون لفظ افتراضي Virtual بدلا من إلكتروني للالالة على افتراض وجود المعلم وجها لوجه، وحيث أنهم جميعا متباعدون ولا يوجدون عملياً في مكان واحد

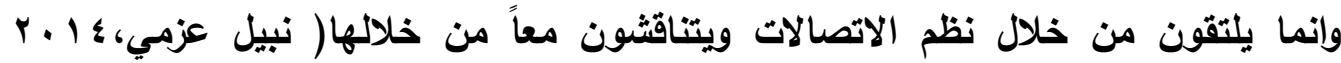
.$(\leqslant \leqslant 9$ 。

ونظراً لتزايد الاهتمام بالتعليم الافتراضي عُقدت العديد من المؤتمرات الدولية الخاصة

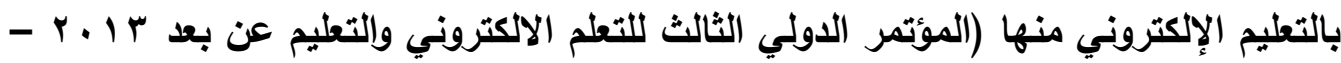


الرياض) تحت شعار" الممارسة والأداء المنثود " ، ومن أهم توصياته ما يلي (المركز

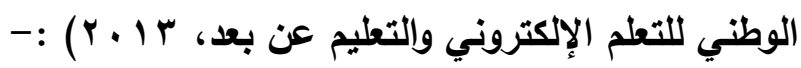

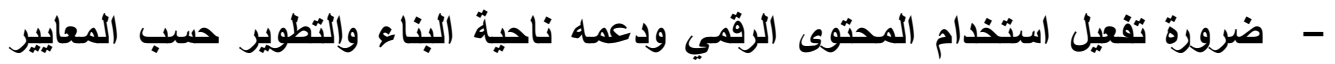
العالمية وتسهيل الوصول إليه وتوفير أدوات بناء المقررات الرقمية.

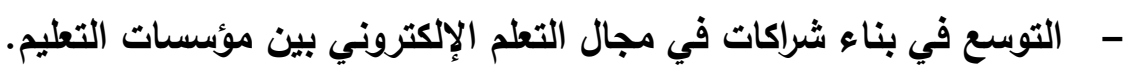

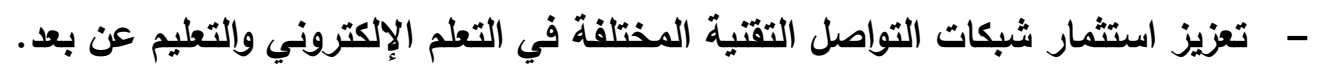

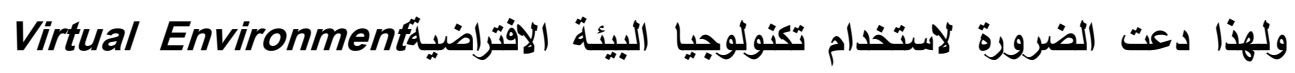

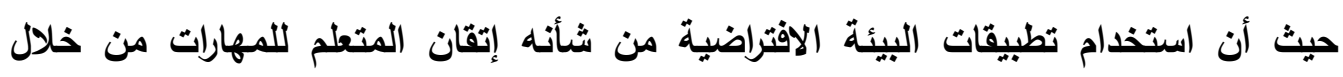

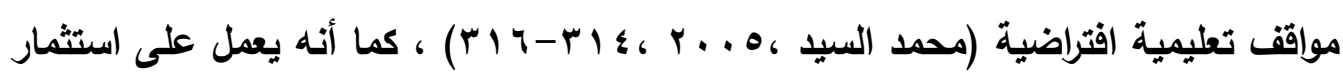

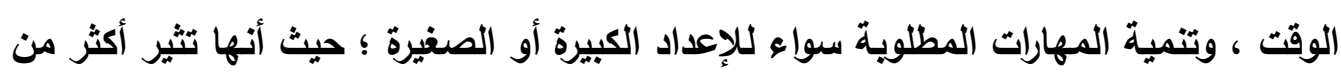

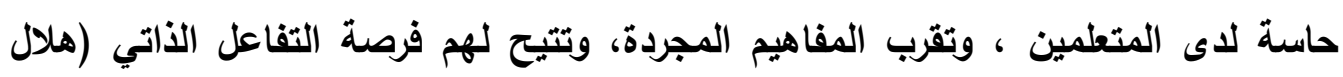

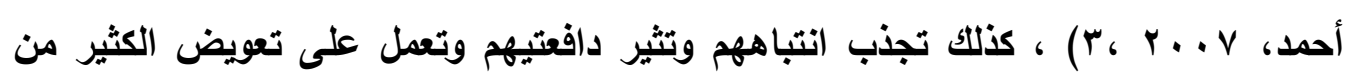

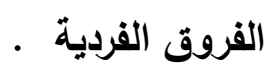
ويمكن توظيف البيئات الافتراضية من خلال نموذج "سوشمان" للأحداث المتناقضة، الذي

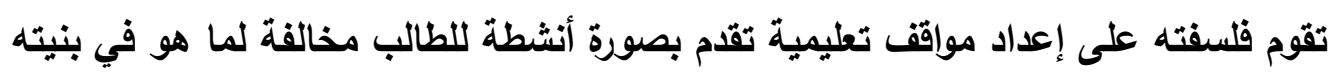

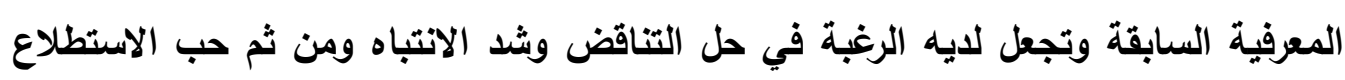

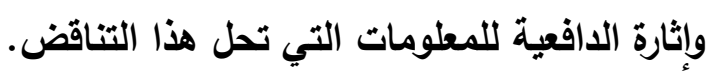

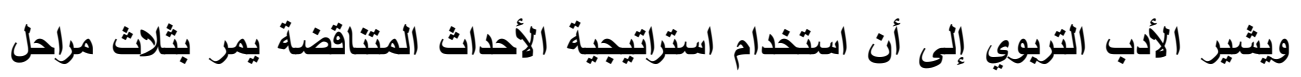

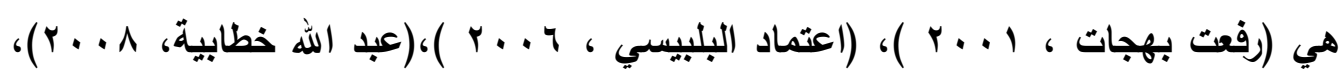

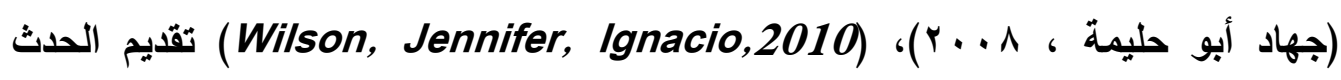
المتناقض ، والبحث عن حل التناقض ، وحل التناقض.

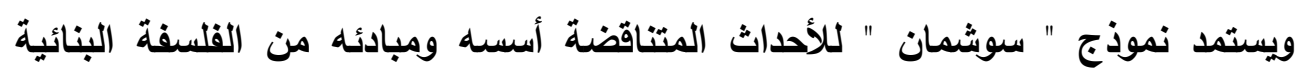

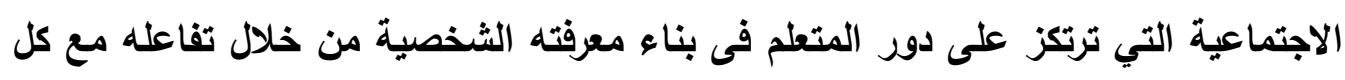
من الأفراد والبيئة المحيطة به، فيمكن للبنائية الاجتماعية بما تقدمه من أفكار ومبادئ ذات مضامين مهمة حول التعليم والتعلم أن توفر ببيئة مناسبة لتطبيقات تكنولوجيا المعلومات التئية والاتصالات في العملية التعليمية. 
ولقد عرف الفكر التريوي في السنوات الأخيرة تحولات تريوية، منها الاهتمام المتزايد بالمفاهيم العلمية لما لها من أهمية كبيرة في تنظيم المعرفة العلمية في صورة ذات معنى، فهي العناصر المنظمة والموجه إلى المعلومات أو المعرفة العلمية التى يتم تقديمها فى حجرة الدراسة، ولذا تؤكد التربية العلمية على ضرورة تعلم المفاهيم بصورة صحيحة (عبد السلام

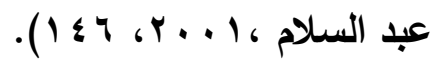
ولقد أشارت دراسات عديدة إلى أهمية تنمية المفاهيم العلمية لاى طلاب المراحل

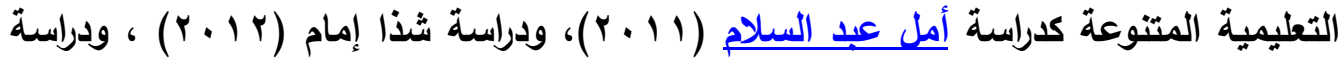

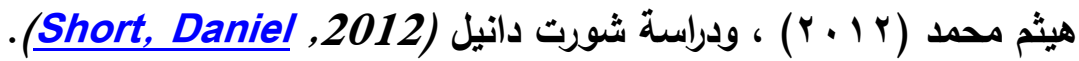
ويعتبر الحس من أرقى الأنشطة العقلية التي يمارسها الإنسان في حياته اليومية بصورة

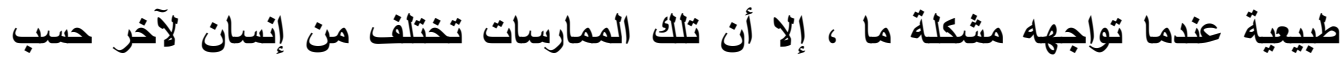
إتقانه لمهاراته التي سبق أن تعلمها، فممارسات الحس مثل باقي الممارسات الحياتية الأخرى التي يتعلمها الإنسان ويتدرب عليها إلى أن يصل إلى مستوى من الدقة والإتقان والمرونة في

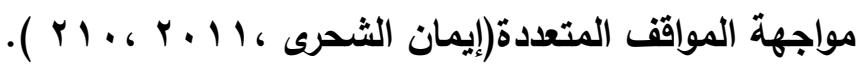
لذلك يجب أن تكون تنمية الحس العلمي هدفاً يسعى تدريس العلوم لتحقيقه ويُخطط للعمل على تنميته لاى المتعلمين منذ الصغر لمساعدتهم على مواجهة المشكلات التي تقابلهم والتنوع في حلها، وعلى معالجة المهام الموكلة إليهم ، وسرعة أدائها، ويالتالي يمتد أثرها طوال حياته، مما ينّمي لاى المتعلم المثابرة وتحمل المسئولية والاستقلالية ويكسبه ثقةً بنفسه ودقة في أدائه ، كما يكسبه القدرة على اتخاذ القرار. ولتنمية الحس العلمي يجب تصميم استراتيجيات تعتمد علي الأنشطة العقلية ، وذلك من خلال توفير فرص تعليمية ايجابية ، هذا وتثير الدراسات إلي ضرورة الانتقال للتعلم المتمركز حول المتعلم ليصبح مشاركاً من خلال بيئة ثرية تحث علي التعلم النشط ، فقد أثشارت دراسة (Newman, D.,1993) خلال التركيز علي الأنثطة العلمية مما يساهم في إكسابهم الحس العلمي والقدرة علي تحمل

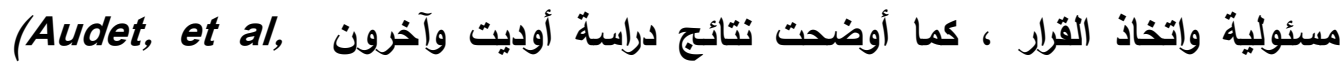
(1996 أن استخدام الكمبيوتر في تدريس الفيزياء كوسيلة تعليمية ساعدت المتعلمين على فهم المفاهيم العلمية ووفرت المناخ الملائم لنمو الحس العلمي لاى المتعلمين. 
وفى ضوء ما سبق فقد استشعر الباحث بأن هناك حاجة ماسة لتنمية المفاهيم العلمية والحس العلمي لاى التلاميذ من خلال بيئة تعلم افتراضية قائمة على استخدام نموذج

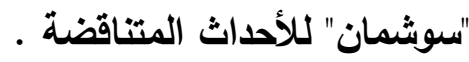

مشكلة البحث: بالرغم من أن تنمية المفاهيم العلمية من الأهداف المهمة فى التربية العلمية وتدريس العلوم إلا أن نتائج بعض البحوث وإلدراسات قد أثبتت وجود ضعف فيه في مستوى هذه الأنهات المهارات

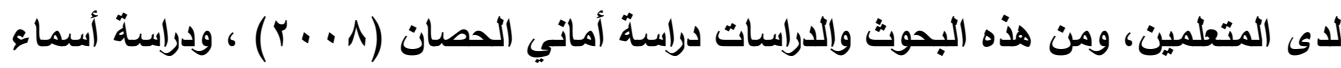

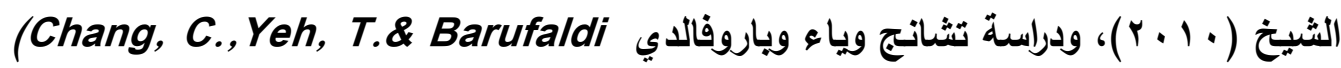

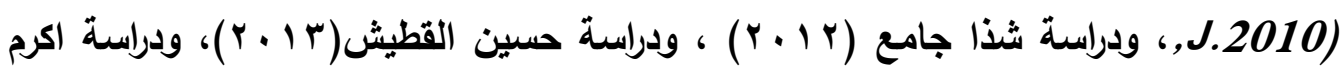

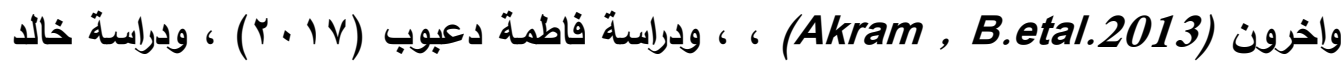

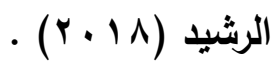
وقد أرجعت هذه البحوث واللاراسات هذا الضعف في المفاهيم العلمية إلى طرق التدريس المستخدمة في التدريس عامة، وتدريس العلوم خاصة ، وفى ضوء ذلك فقد استثعر الباحث بأن هناك حاجة ماسة لتنمية المفاهيم العلمية لدى التلاميذ من خلال بيئة تعلم افتراضية

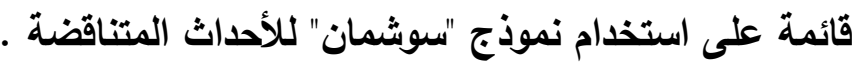
وعلى الجانب الآخر يهذف تدريس العلوم إلى تنمية الصس العلمي لاى المتعلمين ، لذلك اهتمت بعض البحوث والدراسات بتنمية الحس العلمي نتيجة لما اتضح لها من تلنى مستوى الحس العلمي لاى التلاميذ فيه، ومن هذه الدراسات: ودراسة آش (Ash A.,2004)،

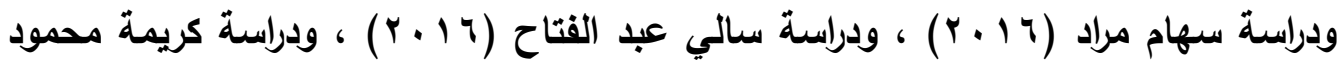

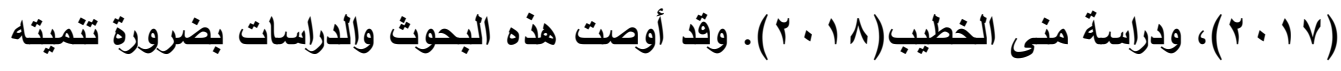
جواتب الحس العلمي لاي التلاميذ في المراحل التعليمية المختلفة من خلال استخدام استراتيجيات ونماذج حديثة .

تحددت مشكلة البحث في ضعف مستوى المفاهيم العلمية، والحس العلمي لاى تلاميذ الصف الثاني الإعدادي ، لذا حاول البحث الحالي التظلب على هذا الضعف من خلال استخدام بيئة تعلم افتراضية قائمة على نموذج "سوشمان" للأحداث المتناقضة في تدريس وحدة "الصوت والضوء "، والتعرف علي فاعليتها في تنمية المفاهيم العلمية والحس العلمي لدي تلاميذ الصف الثاني الإعدادي. 


\section{سؤالا البحث:}

حاول البحث الحالي الإجابة عن السؤلين التاليين:

1- ما فاعلية استخدام بيئة تعلم افتراضية قائمة على نموذج "سوشمان "لأحاثاث المتناقضة

في تدريس العوم على تنمية المفاهيم العلمية لاى تلاميذ الصف الثاني الإعدادي ؟

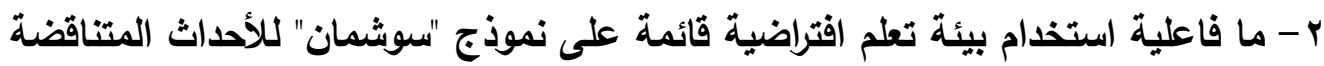
في تدريس العلوم على تنمية الحس العلمي لاى تلاميذ الصف الثاني الإعدادي ؟ هدفا البحث : هابث: هاف البحث الحالي إلي: 1- تنمية بعض المفاهيم العلمية لاى تلاميذ الصف الثاني الإعدادي. ب - تنمية الحس العلمي لاي تلاميذ الصف الثاني الإعدادي. فرضا البحث:

حاول البحث الحالي اختبار صحة الفرضين التاليين: 1- يُوجد فرق دال إحصائياً عند مستوي (ه ...) بين متوسطي درجات تلاميذ المجموعة

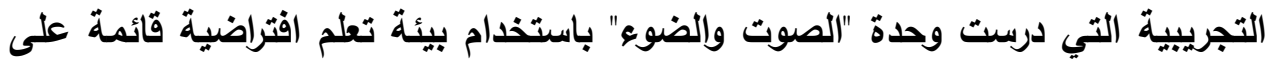

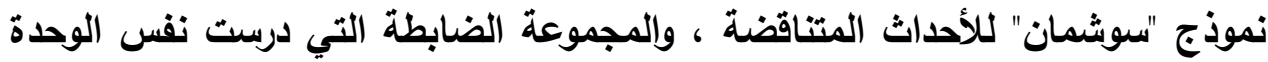

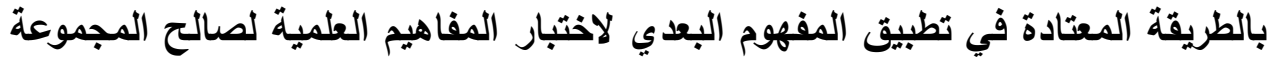
التجريبية. r-يُوجد فرق دال إحصائياً عذد مستوي (ه ..) بين متوسطي درجات تلاميذ المجموعة

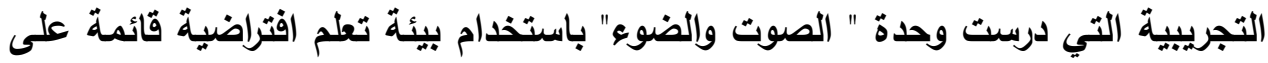

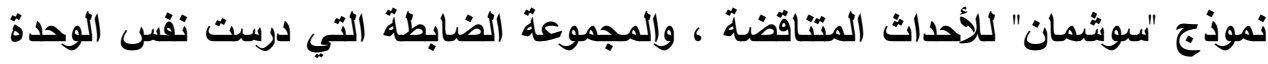

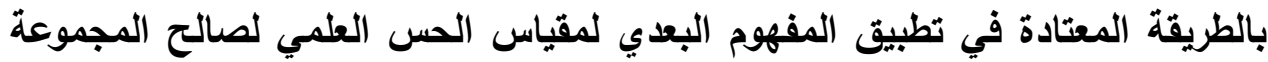

1- قد يُفيد القائمين علي تخطيط وتصميم مناهج العلوم في إعداد وحدات باستخدام بيئة تعلم افتراضية قائمة على نموذج "سوشمان" للأحداث المتناقضة لاى تلاميذ الصف الثاني الإعدادي الأمر الذي قـ يساعد علي تحقيق الأهداف التي تسعي مادة العلوم 
r- يمكن أن يوجه نظر معلمي العلوم بالحلقة الإعدادية إلى أهمية تنمية المفاهيم العلمية

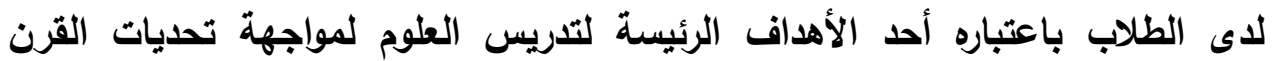

$$
\text { الحادي والعشرين. }
$$

r- يقلم لمعلمي العلوم نماذج إجرائية لكيفية تخطيط وتتفيذ استخدام بيئة تعلم افتراضية قائمة على نموذج "سوشمان" للأحداث المتناقضة في التدريس بما يعينهم على الته استخد/مها، والاسترشاد بها لبناء نماذج أخرى. ع - يُقدم قائمة بأبعاد الحس العلمي قد يستفيد منها القائمين على تصميم مناهج العلوم. ه- ريما يفيد مقومي مناهج العلوم بالحلقة الإعدادية في بناء مقاييس مثل مقياس الحس بلمس العلمي لطلاب الصف الثاني الإعدادي.

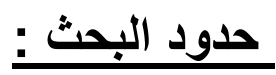

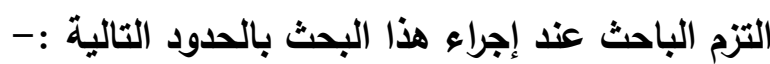
(1) تطبيق تجرية البحث على عينة من تلاميذ الصف الثاني الإعدادي بمدرسة بنهو

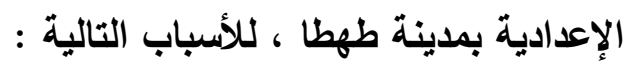
1- تضم هذه المدارس تلاميذ من منطقة جغرافية وسكنية واحدة محيطة بالمدرسة ، الأمر الأي ييسر الحصول على مجموعة متكافئة . r- توزيع التلاميذ داخل الفصول يتم فى بداية العام الدراسي بطريقة تكفل وجود جميع المستويات التحصيلية فى الفصل الواحد الأمر الذى يساعد فى الحصول على مجموعة لونة متكافئة تقريباً فى المستويات المعرفية.

r- تعاون إدارة المدرسة فى اجراء البحث العلمي ، وتقديمها كافة التسهيلات التلازمة. (Y) اختيار وحدة " الصوت والضوء" من كتاب العلوم للصف الثاني الإعدادي فى الفصل

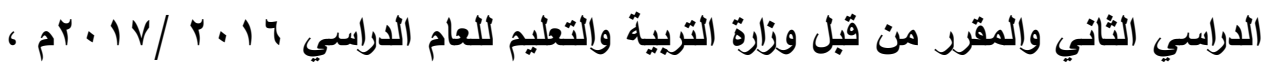
لاحتوائها على العديد من المفاهيم العلمية العديدة. (r) بيئة تعلم افتراضية ( تزامنية ولا تزامنية ) قائمة على النظرية البنائية الاجتماعية

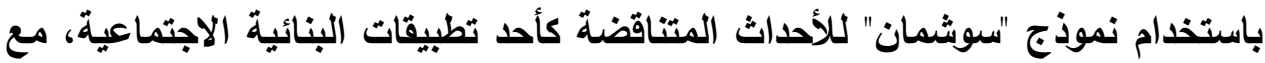
استخدام معمل الكمبيوتز المتطور وغرفة مناهل المعرفة من خلال موقع الكتروني يتضمن الأدوات التالية:الوحدة الدراسية- مكتبة الفيديو- أدوات التقويم- المكتبةالحوار والدردشة - مواقع ذات صلة. 
(؛) عينة من تلاميذ الصف الثاني الإعدادي بمدرسة بنهو للتعليم الأساسي مركز طهطا،

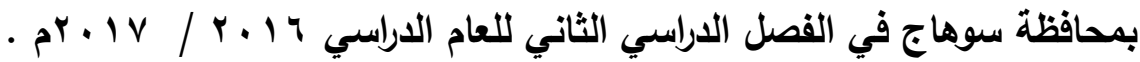

(0) تم تطبيق تجرية البحث فى معمل الكمبيوتر المتطور وغرفة مناهل المعرفة. (†) قياس مستوى تحصيل التلاميذ فى المفاهيم العلمية فى مستويات :اسم المصطلحالأمثلة- تطبيق المفهوم.

قياس مستوى التلاميذ فى أبعاد الحس العلمي في الأبعاد : الاستمتاع- المثابرة- (V)

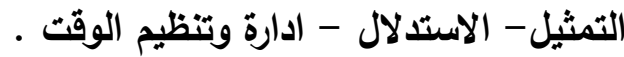
مواد و أدوات البحث :

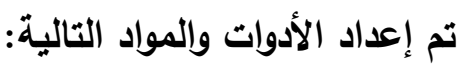

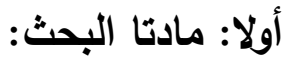
ا. بيئة تعلم افتراضية قائمة على نموذج "سوشمان" من خلال موقع الكتروني (www.elbaz-sohag.com) تلاميذ الصف الثاني الإعدادي . r. دليل المعلم لثرح كيفية تعليم وتعلم وحدة "الصوت والضوء" المقرة على تلاميذ الصف الثاني الإعدادي، وفقاً لبيئة التطلم الافتراضية القائمة على نموذج سوشئمان الثران.

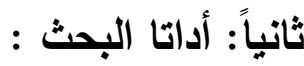

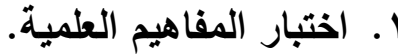

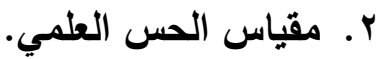
منهج البحث :

اقتضت طبيعة البحث الحالي استخدام المنهج شبه التجريبي لمجموعتين متكافتئين لأنه

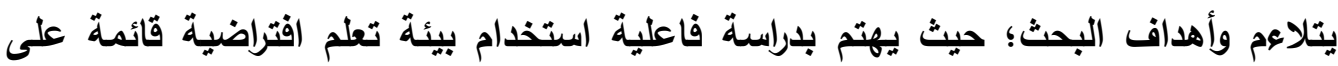
نموذج "سوشمان" للأحداث المتناقضة (متغير مستقل) علي تنمية المفاهيم العلمية والحس العلمي (متغيران تابعان) لاي تلاميذ الصف الثاني الإعدادي في مادة العلوم. 


\section{"Virtual learning environment"} بيئة تعلم افتراضية البحث: بيئة الكترونية تعليمية تمكّن تلاميذ الصف الثاني الإعدادي من استعراض محتوى وحدة " الصوت والضوء" في أي وقت ، ومن أي جهاز حاسوب متصل بشبكة الانترنت ، كما تمكنهم من الاتصال بالمعلم أو زملائهم الذين يارسون نفس الوحدة بوسائل الاتصال المخصصة لذلك وتمكنهم من تقييم أدائهم من خلال وسائل التقييم المتاحة فيها. "Suchman model" نموذج سوشمان

نموذج تدريس تُرس به وحدة " الصوت والضوء " يعتمد على الأحداث المتناقضة، وإثارة تفكير طلاب الصف الثاني الإعدادي بدافع الحاجة إلى المعرفة لحل التناقض بين الحدث المتناقض ويين ما هو متوقع أن يكون صحيحاً .

\section{"Discrepant Events" الأحداث المتناقضة}

مواقف تعليمية خاصة بوحدة " الصوت والضوء " تقلم بصورة أنثطة لطالب الصف الثاني الإعدادي مخالفة لما هو في بنيته المعرفية السابقة و تجعل لايه الرغبة في حل التناقض و شد الانتباه إلى المعنى العلمي للمفاهيم العلمية السليمة. "Scientific Concepts المفهوم العلمي اسم أو لفظ أو رمز لبعض الأفكار الرئيسية التي تعبر عن خصائص مشتركة لمجموعة

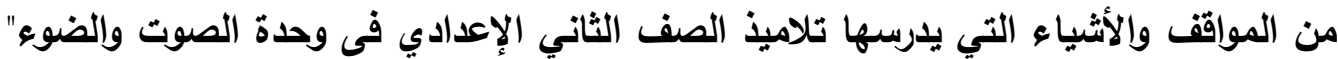
باستخدام استراتيجية الأحداث المتناقضة ، ويقاس بالارجة التي يحصل عليها التلاميذ في اختبار المفاهيم العلمية المعد لذلك.

\section{"Scientific Sense}

الحس العلمي

يُعرف الحس العلمي إجرائياً بأنه: قدرة تلميذ الصف الثاني الإعدادي على إصدار حكم وانتقاء الطرق الصحيحة للوصول إلى حل مشكلة علمية واتخاذ قرار فى أسرع وقت ممكن معتمدا على تمثيل المعلومات باستخدام الرموز أو المخططات والاستدلال والمثابرة والاستمتاع بالعمل العلمي والاستخدام الأمثل للوقت، ، نتيجة دراسته وحدة "الصوت والضوء" باستخدام

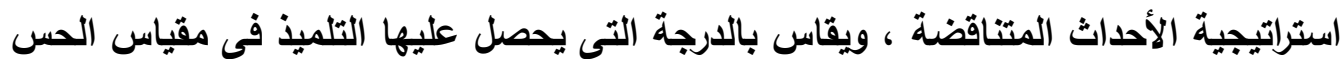
العلمي المُعد لذلكـ. 
إجراعات البحث:

للإجابة عن سؤال البحث واختبار صحة الفرض تم إتباع الخطوات التالية :-

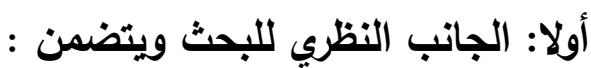
بيئة التعلم الافتراضي ، والنظرية البنائية الاجتماعية ، ونموذج "سوشمان" للأحداث المتناقضة، والمفا هيم العلمية والحس العلمى.

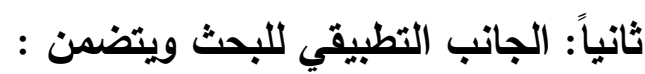
ا ـ إعداد بيئة تعلم افتراضية باستخدام نموذج "سوشمان" لتعليم وتعلم وحدة "الصوت

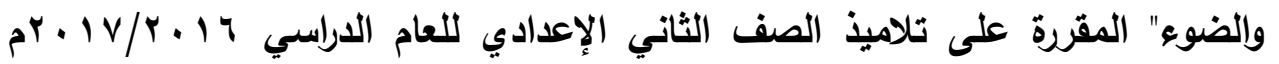
وعرضها على المحكمين للتأكد من مناسبة الأهداف والأنشطة والتقويم ومدى إتقان مهارات البرمجة فيها وتوافقها مع خصائص المرحلة العمرية للتلاميذ. r. إعداد دليل لمعلم العلوم لشرح كيفية تعليم وتعلم وحدة "الصوت والضوء"، وفقاً لبيئة

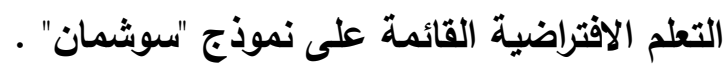
r. . إعداد أداتي البحث وعرضهما على المحكمين للتأكد من صلاحيتهما للتطبيق على تلاميذ

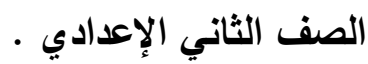
ء. إجراء التجربة الاستطلاعية لضبط أدوات البحث إحصائياً . ه. اختيار عينة البحث عشوائياً من تلاميذ الصف الثاني الإعدادي وتقسيم العينة إلى إلى مجموعتين متكافئتين إحداهما تمثل المجموعة التجريبية التي تدرس وفقا لبيئة تعلم افتراضية قائمة على استخدام نموذج "سوشمان" للأحداث المتناقضة، والأخرى تمثل المجموعة الضابطة التي تدرس بالطريقة المعتادة في تدريس نفس الوحدة.

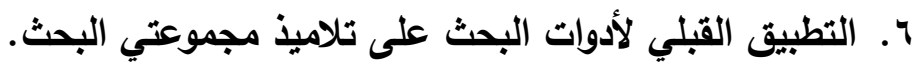

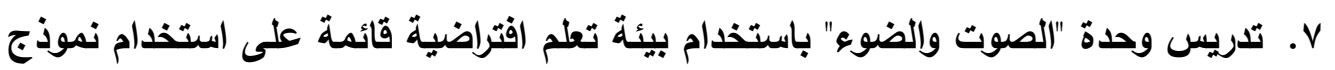

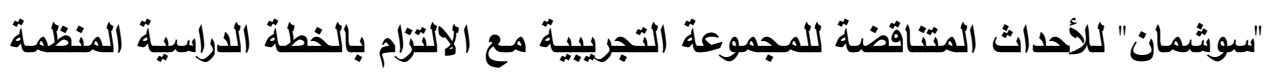

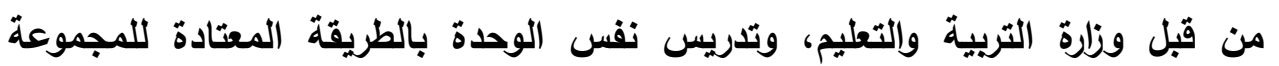
الضابطة. ^. التطبيق البعدي لأدوات البحث علي تلاميذ مجموعتي البحث. 9. معالجة النتائج إحصائيا وتحليليها وتفسيرها. 
• 1. تقديم التوصيات في ضوء ما أسفر عنه البحث من نتائج البحث.

أولاً: بيئة التعلم الافتراضية النظري

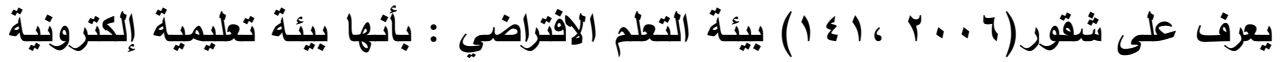
تعتمد على الإنترنت وتوفر للطالب التفاعل الحي المباشر مع المعلم والمحتوى التعليمي والأقران مهما باعدت بينهم المسافات. ويمكن تعريف بيئة التعلم الافتراضية إجرائياً بأنها بيئة تعلم إلكترونية تعتمد على تصميم موقع إلكتروني تفاعلي يتم نشره على شبكة الإنترنت ، وتُبنى فيه المعلومات على شكل صفحات ديناميكية ، وتوفر نوعاً من التفاعل بين المشاركين من خلال تقنيات متعددة، تُمكن التلميذ من قراءة الأهداف واللروس التعليمة وحل الواجبات وإرسال المهام وإلتحاور.

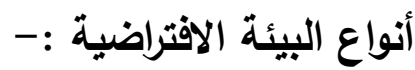

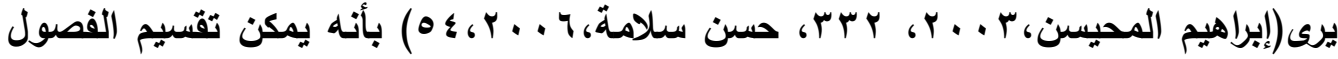
الافتراضية حسب الأدوات والبرمجيات والتقتيات المستخدمة فيها إلى: 1. الفصول الافتراضية غير التزامنية (Asynchronous) ويطلق عليها البعض بأنظمة التعليم الأتي : والتي تمكن الطلبة من مراجعة المادة

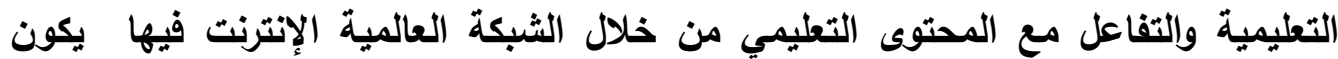
التعليم والتفاعل غير تزامني وهذه الفصول لا تتقيد بزمان ولا مكان ، لذا فهي تستخدم برمجيات وأدوات غير تزامنية تسمح للمعلم والطالب بالتفاعل معها دون حدود للزمان والمكان ، ومن أمثلة هذه الأدوات ساحات الحوار والاخول في مناقشات سواء مع المعلم أو الطلبة فيما بينهم، وقائمة المراسلات بين المعلم وطلابه ويين الطلاب أنفسهم . r. . الفصول الافتراضية التزامنية (Synchronous) هي فصول شبيهة بالقاعات الدراسية يستخدم فيها المعلم والطالب أدوات ويرمجيات مرتبطة بزمن معين (أي يشترط فيها وجود المعلم والطلاب في الوقت نفسه دون حدود

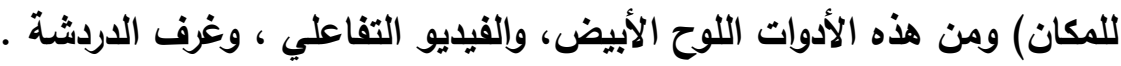




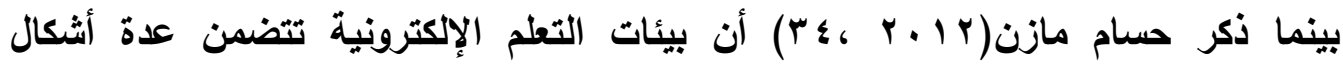
ومستويات للتفاعل وضحها في الثكل التالي:

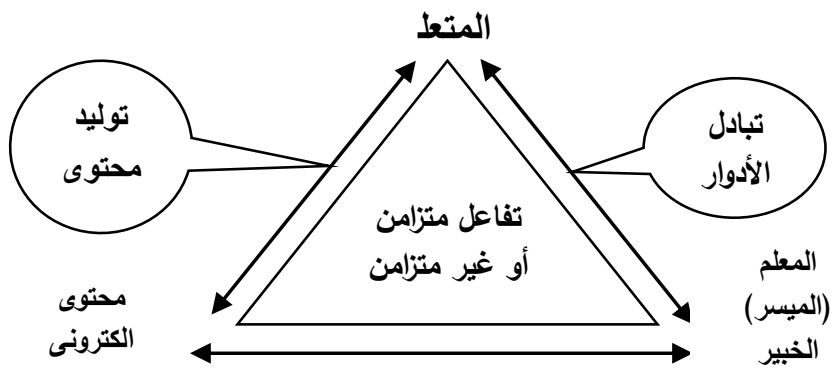

شكل (1) أثكال ومستويات التفاعل في بيئة التعلم الإكترونية

ويتضح من الشكل أهمية إثرالك المتعلم في عملية تعلمه بمساعدة المعلم من خلال المحتوى الإكتروني ومصادر التعلم المتعدة ومن خلال آليات تواصل متعددة والتي تمكن المتعلم من التواصل مع المعلم ومع زملائه المتعلمين. ثانياً: البنائية الاجتماعية (Social constructivism):

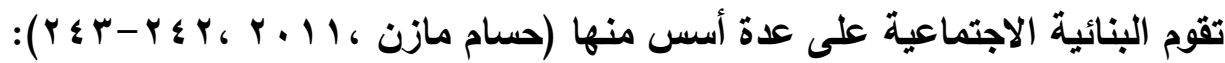

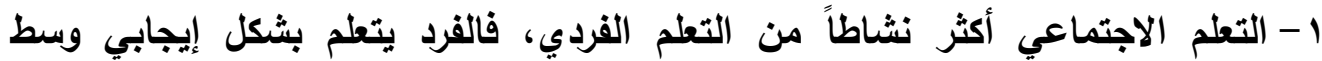
مجموعة من الأقراد كزملائه ووالديه. ץ- تؤكد البنائية الاجتماعية على المعارف المنظمة التي تراكمت ولا تزال تتراكم ويكمل

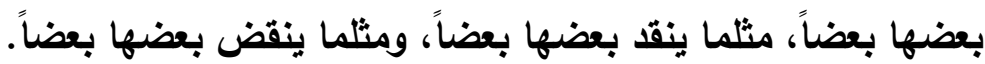

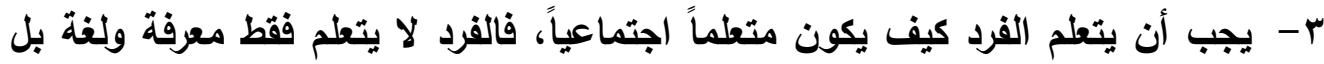
يكتسب أيضاً مهارة حول تعليم نفسه كيف يستفيل من البيئة الاجتماعية المحيطة ع - تؤكد البنائية الاجتماعية على أن أنظمة المعرفة المتعددة، ليست إلا تركيبات ذهنية إنسانية وأن الصورة التي صيغت - ولا تزال تصاغ- فيها المعارف في أنظمة المعرفة جميعها تمت وفقاً لمقتضيات أو قيود كثيرة، منها: سياسات الحكم، والأيدولوجية السائدة في المجتمع، والقيم الاينية والخلقية التي يؤمن بها من يتصدون لصنع المعارف

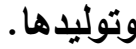


ومما سبق يتضح أن تعلم الأفراد كمجموعة يفوق تعلم كل منهم علي حدة ، وأن المعرفة

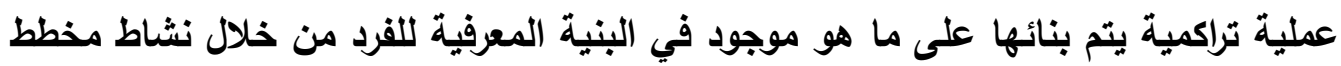
له، وتحدث عملية التعلم نتيجة التكيف بين ما هو موجود بالفعل والمعرفة الجديدة ، كما تحدث نتيجة النقاش والحوار بين المعلم والطلاب ويعضهم البعض. البنائية الاجتماعية والتعلم الالكتروني: توضح دراسات عديدة أن البنائية بما تقدمه من أفكار ومبادئ ذات مضامين مهمة حول التعليم، توفز بيئة ملائمة لتطبيقات تكنولوجيا المعلومات والاتصالات في العملية التعليمية، وهذا ما بينّته دراسة سعود الزهراني (ج . r) من أن التطور المذهل في تكنولوجيا المعلومات

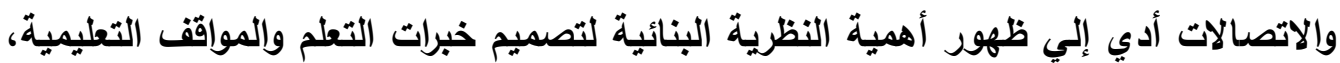
وتطور دور المعلم ليشمل توظيف الخبرات السابقة للمتعلمين في المواقف التعليمية وريطها بالتعلم الجديد لمساعدتهم علي التعلم المتكامل، وتقديم مواقف وخبرات ومشكلات حقيقية وغير حقيقة تساعد المتعلمين علي التفكير الايجابي، وتقويم تقدم التعلم تقويماً بنائياً. إن توظيف هذه الوسائط في العملية التعليمية كأدوات لتحليل المواقف وتفسير المعرفة الشخصية للمتعلم، وتقديم ما يعرفه للآخرين يسهل معالجة المعرفة لاي المتعلمين. وأوضحت دراسة سمية أحمد (؟ . . † ) فعالية استخدام النموذج البنائي الاجتماعي في تصويب بعض التصورات الخاطئة لدي طقل الروضة باستخدام المحاكاة الكمبيوتر، وأرجعت الباحثة فعالية النموذج إلي جعل المتعلم محور العملية التعليمية، وإلي استخدام برامج الكمبيوتز في عملية التعليم.

كما يمكن توفير بيئة تعلم علي الانترنت مبنية علي مداخل البنائية والبنائية الثقافية الاجتماعية من خلال استخدام برامج التعامل الثخصية ويرامج التعاون علي الانترنت كالمنتديات وغيرها(Staupe, A., Hernes, M. , 2000 -6 2000 . وهذا ما أكدته دراسة ليو (Liu, 2005) حيث أظهرت نتائجها فعالية نموذج التلمذة أو التمهن المعرفي ( أحد نماذج البنائية الاجتماعية) المبني علي الويب في تحسين وتطوير أداء المعلمين قبل الخدمة. 
ثالثاً: استراتيجية الاحداث المتناقضة (نموذج سوشمان): تقوم استراتيجية الاحداث المتناقضة على إعداد مواقف تعليمية تقدم للتلميذ بصورة مخالفة لما هو في بنيته المعرفية السابقة وتجعل لايه الرغبة في حل التناقض وشيد الانتباه

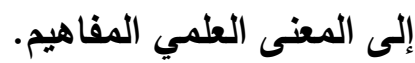

وتثير الأحداث المتناقضة مثاعر قوية لاي المتعلم للملاحظة وحافز داخلي لمعرفة المزيد عن الكيفية التي تم بها هذا الحدث حيث ينمو لديه حب الاستطلاع لحل هذا التتاقض وعندما

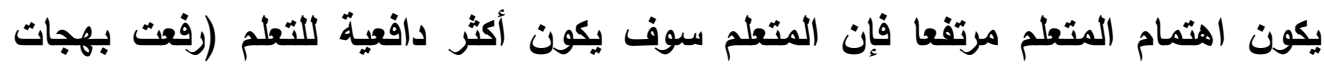

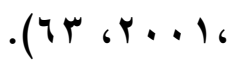
ويمكن تحقيق العديد من الأهداف التريوية عن توظيف طريق الاحداث المتناقضة في التدريس ومنها ، تنمية قدرات حل المشكلات، لعب دور العالم الصغير، تنمية قدرة التساؤل،

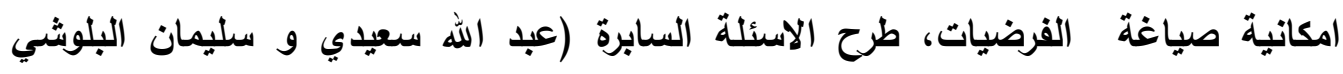

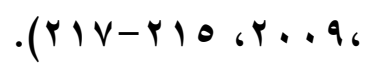

ويمكن تعريف الأحداث المتناقضة إجرائياً بأنها: مواقف تعليمية محيرة ومثيرة يمر بها المتعلم بحيث تأتي نتائجها بثكل مخالف لتوقعاته تثير الدافعية وحب الاستطلاع لاديه لحل هذا التناقض من قبل طالب الصف الثاني الإعدادي العام في مادة العلوم . الأسس الفلسفية لاستراتيجية الاحداث المتناقضة (نموذج سوشئ الفئمان): تستمد استراتيجية الأحاثاث المتناقضة أسسها ومبادئها من الفلسفة البنائية والبنائية

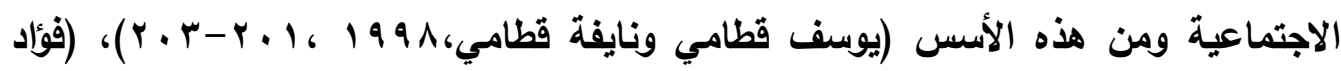

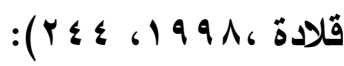
1- يأتي التلاميذ إلى المواقف التعليمية وهم يحملون معارف، ومشاعر ومهارات متنوعة ومن هذه المعارف والمشاعر والمهارات ينبغي أن تبلأ عملية التعلم.

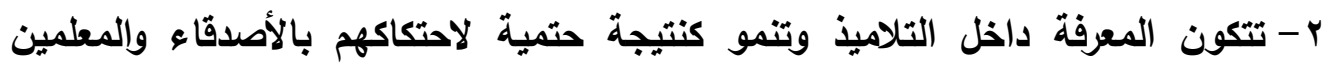
والبيئة المحيطة بهم. r- إن البنية المعرفية لاى المتعلم تقاوم أي تغير بثدة ، إذ يتمسك المتطم بما لديه من

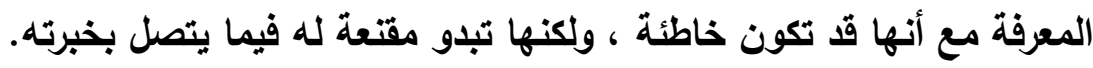


צ- إن وضع المتعلم في موقف تعليمي يقدم فيه ما يناقض ما لايه من معرفة مسبقة يحدث له عدم الاتزان ، وفي هذه اللحظة ينشط عقل المتعلم سعيا وراء الاتزان. ه- يستخدم المتعلم الخبرات السابقة في فهم الأفكار والمعلومات الجديدة ، ويالتالي يمكن أن يحلث التعلم عندما يتم تغيير أفكار المتعلم المسبقة ، وذلك عن طريق إما تزويد المتعلم

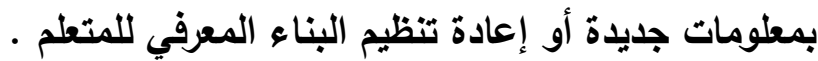
ويتضح مما سبق أن الخبرات السابقة للمتعلمين تعتبر شرط أساسي لإحداث التعلم المرغوب واستيعاب الخبرات الجديدة وأن المتعلم يأتي للمدرسة ولديه معرفة مسبقة عن لأنين الأحلاث والظواهر المحيطة به ،وعند وضعه في موقف تعليمي مناقض لما لديه من معرفة

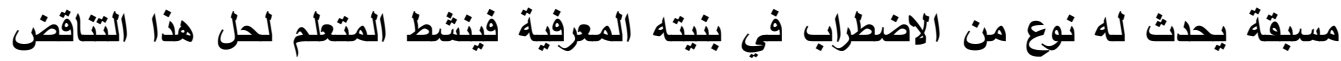
واستعادة توازنه، مما يكسبه مهارات متنوعة وتساعده على تعديل المفاهيم الخاطئة لايه، وتتمى لايه حس علمي نحو العلوم. القيمة التريوية لاستراتيجية الأحداث المتناقضة علئة يحقق استخدام استراتيجية الأحداث المتناقضة عديد من النواتج التعليمية منها: ا - تنمية التحصيل والمعرفة العملية للطلاب (عبد الله خطابية، فاضل عبيدات، ج . . ؟ ) r - تنمية الاستقصاء العلمي وعمليات العلم والدافعية للإنجاز(أمنيه الجندي ، نعيمه أحمد،

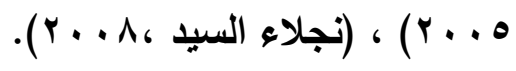

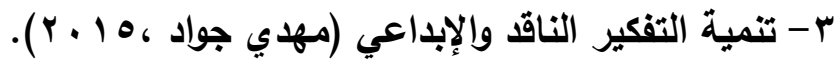
ع - تتمية المفاهيم العلمية ، وتعديل التصورات البديلة لبعض المفاهيم العلمية (تهاني

$$
\text { العبوس ، ورؤوف العاني ، ب ا ـ ب). }
$$

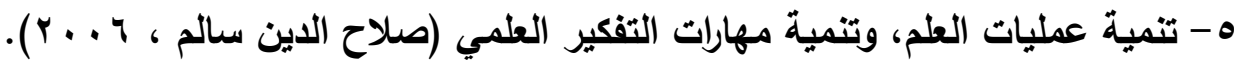
المفاهيم العلمية

تُعد المفاهيم العلمية من أهم نواتج العلم التي يتم بواسطتها تتظيم المعرفة العلمية واختصارها في صورة ذات معنى، وللمفاهيم العلمية دور في نمو المعرفة العلمية لأنها لغة العلم ومفتاح المعرفة العلمية الحقيقية واللغة المشتركة بين العلماء وغيرهم، ويرجع الاهتمام بتعليم المفاهيم الأساسية وتعلمها إلي أنها أكثر ثباتاً، وتقلل كم الحقائق التي يطلب من المتعلم الإلمام بها، وتثكل قاعدة أساسية لتعلم المبادئ والتعميمات. 
ومن الحقائق الثابتة أن تكوين المفهوم يبدأ منذ الولادة، فالطقل الصغير في محاولته فهم العالم من حوله واستكشاف ما يحيط به من مثيرات يتطلع إلى امتلاك نظام من الاستجابات الموحدة للتعامل مع البيئة المحيطة به. ولذلك كان التركيز على تدريس المفاهيم العلمية، والتعرف على خصائصها وطريقة تكوينها وإكسابها للمتعلمين هو أهم أهداف التربية العلمية فى جميع مراحل التعليم المختلفة

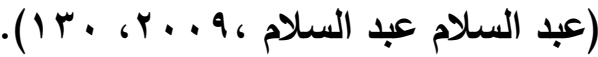

$$
\begin{aligned}
& \text { أهمية تعلم المفاهيم العلمبة: }
\end{aligned}
$$

يؤدى تعلم المفاهيم لريط الحقائق العلمية وتصنيفها ، والتظلب على كثرة المعلومات ، وقد يؤدى هذا إلى إيجاد منهج تكاملي للمعرفة ، كما يساعد في تصميم المواقف التعليمية المختلفة فى تدريس العلوم ، فهي الوحدات الأساسية في بناء واختيار الأنشطة

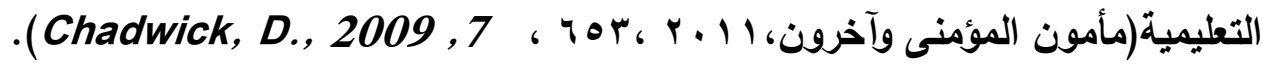
كما أن تعلم المفاهيم يعمل على زيادة فهم المواد العلمية وطبيعة العلم ، وتبسيط البيئة وتقلل من تعقيدها ، وتنمية التفكير العلمي من خلال التساؤل والبحث والتجريب، واكتساب لهيب بعض الاتجاهات الايجابية وتنميتها لدى التلاميذ نحو العلم والعلماء (عواطف عبد

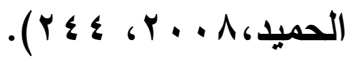

كما أنها تساعد على التعلم الذاتي والتربية العلمية مدى الحياة ، وهى أساسية لتكوين القوانين والنظريات العلمية ، كما أن لها علاقة كبيرة بحياة التلاميذ أكثر من الحقائق المتناثرة استراتيجيات وطرق ووسائل تنمية المفاهيم العلمية : يوجد عديد من الاستراتيجيات والطرق والوسائل التعليمية، تسهل من عملية تكوين المفهوم

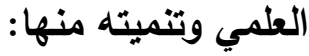

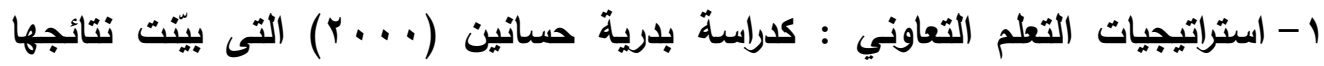
فاعلية التعلم التعاوني فى تنمية التحصيل وتكوين الميل نحو مادة العلوم لدي تلاميذ الصف الرابع الابتدائي، ودراسة محمد عطا (17 ـ ب) التي أشارت إلى فاعلية التعلم التعاوني فى اكتساب المفاهيم لتلاميذ الصف الثاني الإعدادي. 


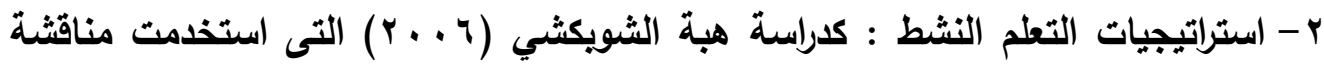
المجموعات الصغيرة لتتمية المفاهيم العلمية للتلاميذ وتنمية الاتجاهات التعاونية لاى الدى

$$
\text { طلاب المرحلة الاعدادية. }
$$

ץ- البرمجيات التعليمية: كلراسة نجلاء عبد القوى (11) (11) التي استخدمت برمجية كمبيوتر تعليمية لتنمية المفاهيم العلمية لتلاميذ الصف الأول الإعدادي.

ع - الاستقصاء: كلراسة جريج مولوتسكى Golotsky (2011) التى استخدمت الاستقصاء العلمي في منهج الفيزياء فى وحدتي الكهرياء والمغناطيسية لاى طلاب الفصول الثانوية في جنوب نيوجيرسي في تنمية المفاهيم العلمية.

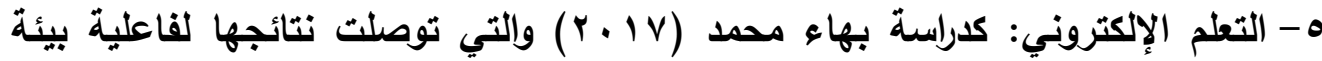
أدوات المقرر الثبكي فى تنمية المفاهيم العلمية لتلاميذ الصف الثاني الإعدادي.

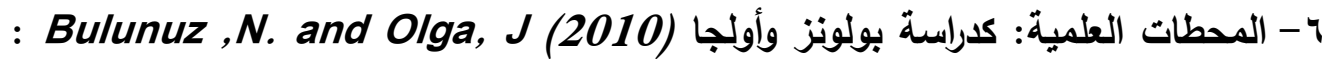
والتي توصلت نتائجها لفاعلية استراتيجية المحطات العلمية في إكساب معلمي العلوم للمرحلة الابتدائية بعض المفاهيم العلمية مثل الأرض والفضاء .

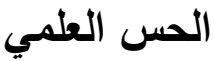

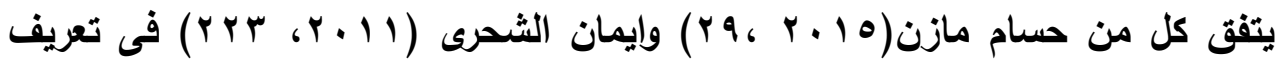
الحس العلمي بأنه القرة على إصدار حكم وإنتقاء الطرق الصحيحة للوصول إلى حل المشكلة واتخاذ قرار يعتمد على السبيبة في أسرع وقت ممكن، ويستال على وجوده من خلال الممارسات التي يقوم بها المتعلم ، وتثثير أغلبها إلى أدوات ذهنية وعمليات قائمة على ولى الإدراك والأمثلة والوعي. وللحس العلمي ثمانية مكونات هي: الإحساس- الانتباه- الإدراك- - الوعي- حل

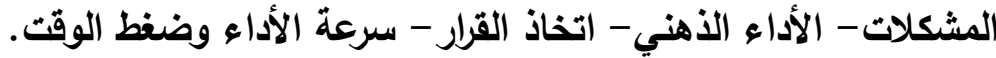

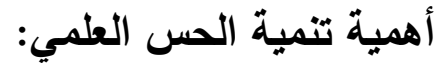
تعتبر ممارسات الحس مثل باقي الممارسات الحياتية الأخرى يتعلمها الإنسان ويتدرب عليها، وينميها حتى يصل لمستوي الدقة والإتقان والمرونة في مواجهة المواقق المتعدادة،

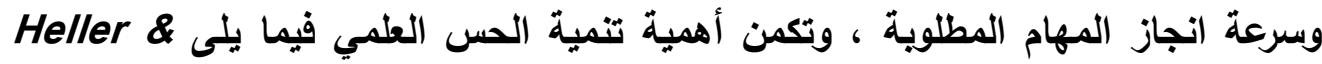

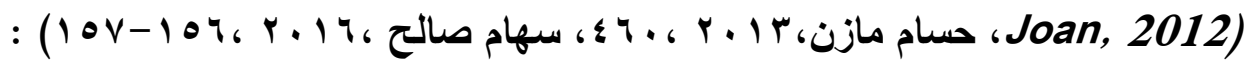


1- مساعدة المتعلم على تنمية مهارات التفكير والأنشطة العقلية بحيث يكون المتعلم قادراً على استخدام عاداته العقلية ومعرفته بكفاءة. r - القضاء على التفكير الثائع والتعام لاى المتعلم (الحس العام)، الأى يعتمد على فطرته

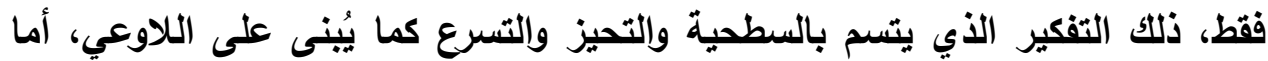
الحس العلمي فإنه يعتمد على الإدراك المبني على الأمثلة واللوعي.

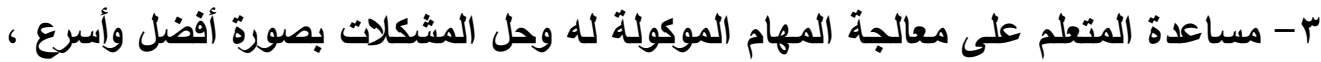
وأن يتظلب على نواحي القصور في أداءاته الذهنية ، مما ينمي لاى المتعلم المثابرة

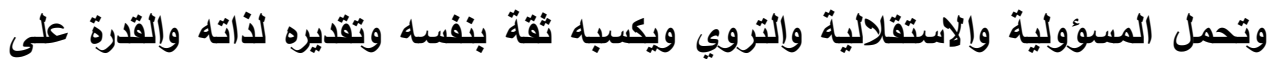
اتخاذ القرار المناسب في المواقف الحياتية اليومية . ع - مساعدة المتعلم على تنمية قراته على استخدام لغة العلوم بما تحويها من رموز ومصطلحات، فنحن بحاجة إلى متعلم لايه الوعي الكافي لما يقرأه من نصوص علمية مع القرة على استحضار المعنى المناسب من خلال الريط الصحيح بين الفكرة واللفظ والمعنى والرموز •

ويرى الباحث أنه نظراً لأهمية تنمية الحس العلمي ينبغي أن يكون هدفاً يخطط له من خلال بيئة تعلم مناسبة ترستخ ممارسات الحس العلمي من خلال الأدوار التي يقوم بها المعلم على لـي اعتباره الحجر الأساسي للعملية التعليمية ومن قِيل التلاميذ. سمات أصحاب الحس العلمي يطلق على المتعلمين الذين يؤدون ممارسات الحس العلمي أصحاب الحس العلمي حيث يمتلكون بعض السمات الخاصة (David, 2013، Elaine, 2009, 341-342 ، حسام

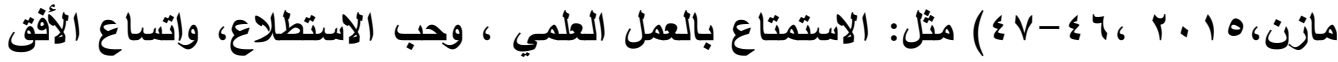
،والمرونة في معالجة المواقف ، وتنوع الاستراتيجيات الذهنية لمعالجة المشكلات ، والقدرة على الاستدلال، والقدرة على تقديم الأدلة العلمية، والقدرة على التوسع والإفاضة ، والقدرة

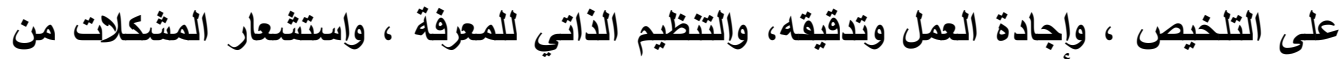
حوله ، واليقظة العقلية ، وسعة الخيال العلمي، والقدرة على التصور المجرد، وتوليد الأفكار ، وتفعيل غالبية الحواس، والمحافظة على الأمان الشخصي، والتحدث بلغة علمية، والمبادرة، 
وتحمل المسؤولية، والمثابرة ، والتريث في إصدار الأحكام، واستقلالية التفكير، وتقديره لذاته، والحس العددي والكيميائي والقيزيائي، والقدرة على الحكم وتقدير النواتج ذهنياً. ويتناول الباحث فى دراسته تنمية جواتب الحس العلمي المتعلقة بالجواتب المعرفية والوجدانية التالية: الاستمتاع ، المثابرة ، التمثيل ، الاستدلال ، ادارة وتتظيم الوقت. استراتيجيات وطرق ووسائل تنمية الحس العلمي يوجد عديد من الاستراتيجيات والطرق والوسائل، تستخدم في تنمية الحس العلمي منها: ا- دراستي آش (Ash, D., 2009), (Ash, D., 2003) إلى أهمية المراكز الاستكثافية والمتاحف والأسرة ودورهم في تنمية مهارات الاستقصاء المكونة للحس العلمي وأهمية المحادثات والتواصل بين الأسرة خلال زيارة المتاحف في تنمية الحس وله - العلمي

r- دراسة جون (Heller \& Joan, 2012) التى توصلت إلى أن استخدام المناقثة والاستقصاء ساعد في تنمية ممارسات الحس العلمي لاى الطلاب في مادة العلوم. r- دراسة لورا وآخرون (Laura, Z., et al., 2013) وتوصلت إلى أنه يمكن تنمية الحس العلمي لاى الطلاب من خلال استخدام معلمي العلوم التجارب العلمية ومشاركة الطلاب في جمع البيانات والوصول للنتائج وتفسيرها وتنفيذ الأبحاث وتزويد قدرة الطلاب على تفسير الظواهر المختلفة عند استخدام معلمي العلوم للوسائل التعليمية والتقنية كالقيديو التعليمي.

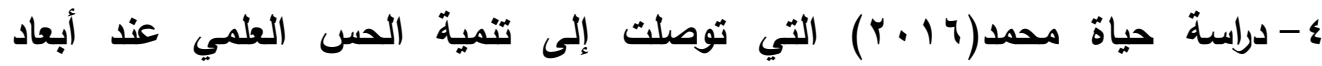
(الاستمتاع-التمثيل- الحس العددي-الاستدلال-احتياطات الأمن والأمان) لاى تلاميذ الصف السادس الابتدائي باستخدام استراتيجيات التفكير المتثعب. ه- دراسة سالي إبراهيم (7 1 ـ Y) والتي هدفت إلى بناء برنامج تنمية مهنية لمعلمي العلوم بالمرحلة الإعدادية قائم علي مدخل المعلم كعالم لتنمية الحس العلمي ويعض متطلبات الكفاءة المهنية لايهج وتوصلت الاراسة إلي فاعلية البرنامج المقترح فى تنمية الحس ماته العلمي ويعض متطلبات الكفاءة المهنية لايهم. 
التعقيب العام على الإطار النظري:

في نهاية الإطار النظري يمكن تدايد أوجه الاستفادة منه في النقاط التالية:

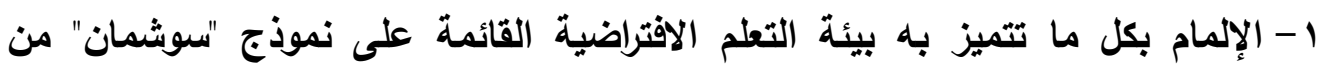
خصائص بهاف التوصل إلى الشكل الأمثل الذي يساعد في علاج مشكلة البحث. r- التعرف على المعلومات بثأن المتغيرات التابعة للأخذ بها في إعداد أدوات البحث.

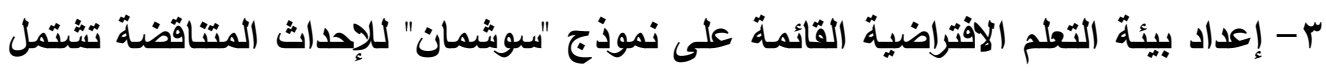
على جميع الآتراحات التي تم استعراضها في المحاور السابقة.

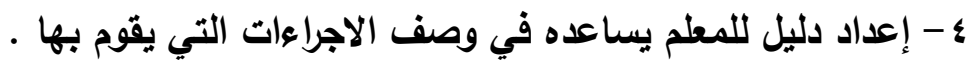

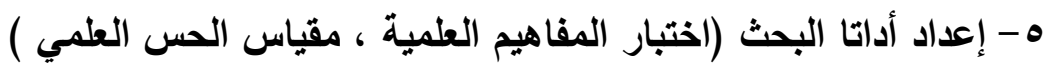

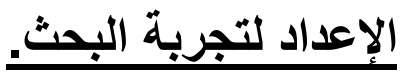
تضمن الاعداد لتجرية البحث ما يلي:1) اختيار المدرسة التي تمت فيها تجرية البحث: تم اختيار مدرسة بنهو الإعدادية المشتركة بمدينة طهطا.

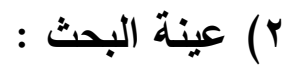
تم اختيار فصلين من فصول الصف الثاني الإعدادي بطريقة عشوائية من بين أربعة فصول

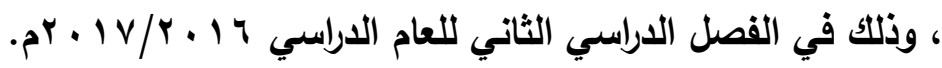

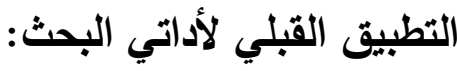
قام الباحث بالتطبيق القبلي لاختبار المفاهيم العلمية في وحدة "الصوت والضوءع" يوم

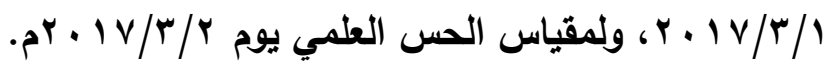
التطبيق البعدي لأداتي البحث:

قام الباحث بالتطبيق البعدي لاختبار المفاهيم العلمية في وحدة "الصوت والضوء" يوم البوائ

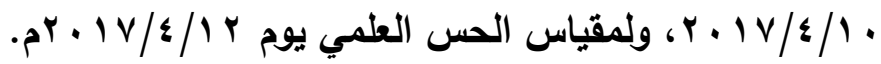




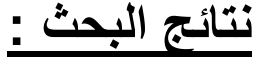

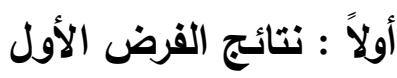

للإجابة عن السؤال الأول البحث، تم إتباع الخطوات التالية:

1. حساب المتوسط الحسابي والانحراف المعياري لارجات المجموعتين التجريبية والضابطة في التطبيق البعدي لكل مستوى من مستويات اختبار المفاهيم العلمية الثلاث ، وفي الاختبار ككل، ثم استخدام اختبار "ت" لمتوسطين غير مرتبطين ن ا= ن ن لمعرفة اتجاه

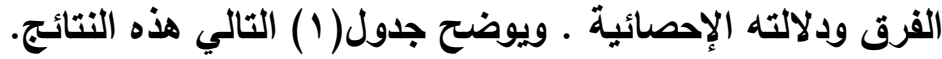

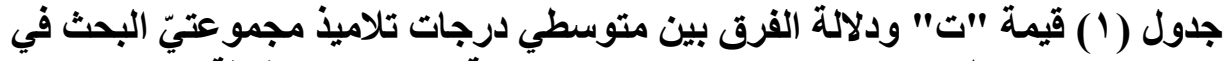

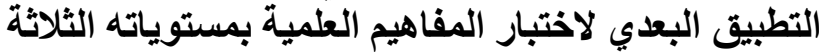

\begin{tabular}{|c|c|c|c|c|c|c|c|c|c|c|}
\hline \multirow{2}{*}{ مستوى الدلادي } & \multirow{2}{*}{ "تيمة" } & \multirow{2}{*}{ "قيمة" } & \multirow{2}{*}{ الحرجية } & \multicolumn{3}{|c|}{ المجموعة الضابطة } & \multicolumn{3}{|c|}{ المجموعة التجريبية } & \multirow{2}{*}{ البيان } \\
\hline & & & & $\varepsilon$ & $r$ & ن & $\varepsilon$ & p & ن & \\
\hline \multirow{4}{*}{ مند } & $V . r V$ & \multirow{4}{*}{$1.7 \mathrm{~V}$} & \multirow{4}{*}{ Tr } & r.q & $1 \% . \varepsilon$ & \multirow{4}{*}{ rr } & Y.r & $1 \wedge . r$ & \multirow{4}{*}{ rr } & المصطح \\
\hline & $9 . \mu v$ & & & r. & $1 \cdot .9$ & & Y.\& & $1 V .0$ & & الأمثلة \\
\hline & $\Lambda .0 \leq$ & & & Y.r & $7 . \wedge$ & & 1.7 & 11.1 & & تطفيق \\
\hline & I r.rV & & & 0. & r. r & & $0 . r$ & $\varepsilon V_{.} \cdot$ & & الاختبار ككل \\
\hline
\end{tabular}

وهذا يعني أن هناك فرقاً دال إحصائياً عندي مستوي (ه . . ) بين متوسطي درجات تلاميذ مجموعة البحث في التطبيق البعدي لاختبار المفاهيم العلمية ككل ولمستويات الاختبار وهى لهى (اسم المصطلح - الأمثلة - تطبيق المفهوم) بعد دراسة وحدة "الصوت والضوء" ، وهذا يدل علي ارتفاع مستوي تلاميذ مجموعة البحث للمفاهيم العلمية بعد استخدام بيئة التعلم الافتراضية القائمة على نموذج سوشمان ، الأمر الذي يقود إلي قبول الفرض الأول من بن فروض البحث.

ولتحديد مدى تأثير البيئة الافتراضية تم حساب حجم أثر استخدام بيئة التعلم الافتراضية القائمة على نموذج "سوشمان "للأحداث المتناقضة في تنمية المفاهيم العلمية لدى تلاميذ 
المجموعة التجريبية، ويوضح جدول (Y) التالي حجم أثر بيئة التعلم الافتراضية القائمة على نموذج "سوشمان" في تنمية المفاهيم العلمية

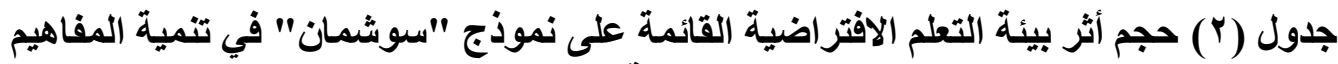
العلمية العية علية

\begin{tabular}{|c|c|c|c|c|}
\hline مستوى الالالة & حجم الأثر & مربع إيتا & قيمة "ت" المحسوبة & الاختبار ومستوياته \\
\hline مرتفع & 1.11 & 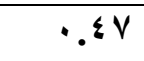 & $V . r v$ & اسم المصطلح \\
\hline مرتفع & r.rq & .09 & $9 . r v$ & الأمثلة \\
\hline مرتفع & r.17 & $.0 \leqslant$ & $1.0 \leqslant$ & تطبيق المفهوم \\
\hline مرتفع & $r .1 Y$ & $\because v 1$ & IY.rV & الاختبار ككل \\
\hline
\end{tabular}

يتضح من جلول (r) أن حجم أثر بيئة التعلم الافتراضية القائمة على نموذج "سوشمان" في تنمية المفاهيم العلمية مرتفع في الارجة الكلية للاختبار ومستوياته

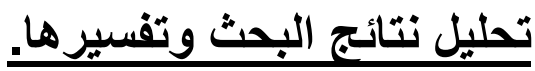
كثفت نتائج اختبار صحة الفرض الأول عن وجود فرق دال إحصائياً عند مستوي (0 . . ) بين متوسطيّ درجات تلاميذ المجموعة التجريبية ودرجات تلاميذ المجموعة الضابطة في التطبيق البعدي لاختبار المفاهيم العلمية لصالح تلاميذ المجموعة التجريبية. كما أثثتث نتائج البحث فاعلية استخدام بيئة التعلم الافتراضية القائمة على نموذج تلهئ "سوشمان" في تنمية المفاهيم العلمية لدى تلاميذ المجموعة التجريبية، ولما كانت المجموعتان التجريبية والضابطة قد درستا وحدة "الصوت والضوء" بعد أن تم ضبط المتغيرات الأخرى بينهما فيما عدا طريقة التريس المستخدمة. ويالتالي فإن التفوق الذى حققته المجموعة التجريبية على المجموعة الضابطة يرجع لاستخدام بيئة التعلم الافتراضية القائمة على نموذج "سوشمان" للإحداث المتناقضة في تدريس وحدة "الصوت والضوء" للمجموعة التجريبية. ويري الباحث أن تفوق المجموعة التجريبية يمكن تفسيره كما يلى ا. تساهم بيئة التعلم الافتراضية القائمة على نموذج "سوشمان" للإحداث المتناقضة على لمانى ايجابية المتعلم ، وقدرته على بناء المعرفة والبناء المفاهيمى من خلال المشاركة والتفاعل. r. تعرض عناصر العالم الواقعي في صورة مبسطة يمكن توفيرها فى حجرة الاراسة تضع المتعلم في مواقف شبيهة بمواقف الحياة الواقعية التي سيمارسها ليقوم بدوره فيها ، 
ويكون مسئولاً عن قراراته ، كما أنها تساعد في التظلب على النفقات المالية اللازمة

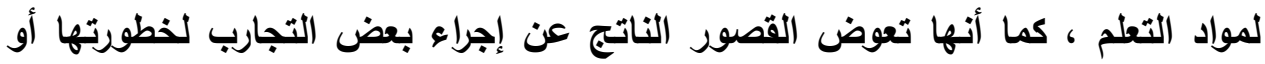

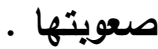

ץ. ريط المتعلم بمصادر الكترونية متنوعة للمطلومات، كالمكتبات الاكترونية، مواقع ذات صلة ، أسهم في إتاحة الفرصة للمتطلم لاكتساب مفاهيم علمية عديدة.

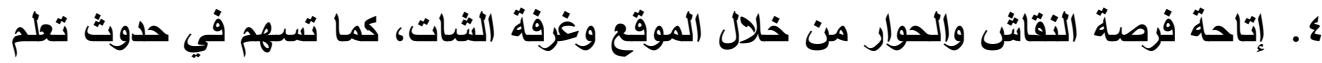
حقيقي نوعى لاى التلاميذ ساعد علي تعلم المفاهيم العلمية. ه. توافر موقع الكتروني (Www.elbaz-sohag.com) أدي إلي تكرار تعلم موضوعات وحدتي البحث، ووجود نوعاً من المرونة في التعلم؛ لأن كل فرد يتعلم حسب خبراتهاته

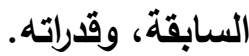
†. تنوع الوسائط التعليمية المستخذمة في موقع (Www.elbaz-Sohag.com) ما بين صور متحركة وصور ثابتة وفلاشات ساعد علي جذب انتباه التلاميذ ، واكتساب المفاهيم العلمية بطريقة سهلة حيث يتم عرض المفهوم مع صورة متحركة أو ثابتة. V. توافز التذذية الراجعة الاكترونية الراجعة ساعد علي تصحيح بعض المفاهيم العيم العلمية الخاطئة لاي التلاميذ، واكتسابها بطريقة سليمة. ثانياً : النتائج الخاصة بمقياس الحس العلمي: للإجابة عن السؤال الثاني للبحث، تم إتباع الخطوات التالية: تم حساب المتوسط الحسابي والانحراف المعياري لارجات المجموعتين التجريبية والضابطة في تطبيق المفهوم البعدي لكل بُّد من أبعاد المقياس (الاستمتاع - المثابرة - التمثيلالاستدلال- ادارة وتتظيم الوقت) لمقياس الحس العلمي ، وفي المقياس ككل، ويوضح الجدول التالي هذه النتائج. 
جدول(r) قيمة "ت" دلالة الفرق بين متوسطي درجات مجموعتيّ البحث في تطبيق المفهوم

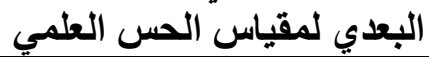

\begin{tabular}{|c|c|c|c|c|c|c|c|c|c|c|}
\hline \multirow{2}{*}{ مستوي الدلاكة } & \multirow{2}{*}{ "المحسوبة "تية" } & \multirow{2}{*}{ "قيمة } & \multirow{2}{*}{ الحرجية } & \multicolumn{3}{|c|}{ المجموعة الضابطة } & \multicolumn{3}{|c|}{ |المجموعة التجريبية } & \multirow[b]{2}{*}{ الأبعاد } \\
\hline & & & & $\varepsilon$ & p & ن & $\varepsilon$ & p & ن & \\
\hline \multirow{6}{*}{ عند مستوي دالة } & YY.VT & \multirow{6}{*}{$1.7 \mathrm{~V}$} & \multirow{6}{*}{$4 r$} & 1.9 & $1 T . \varepsilon$ & \multirow{6}{*}{ MY } & $1 . r$ & YY.q & \multirow{6}{*}{ rr } & الاستمتاع \\
\hline & $r \leqslant . r V$ & & & 1.0 & 14.9 & & 1.7 & rY.o & & المثابرة \\
\hline & 11.94 & & & $1 . \wedge$ & $1 \cdot . \varepsilon$ & & $\because \Lambda$ & IV.1 & & التمثيل \\
\hline & $19 . r T$ & & & r. r & 14.1 & & 1.0 & YY.r & & الاستدلال \\
\hline & 19.r. & & & r. & Ir.r & & 1.0 & YY. & & ادارة وتنظيم الوقت \\
\hline & $r q . r \varepsilon$ & & & ^.r & T.Y & & r.^ & 1.7 .8 & & المقياس ككل \\
\hline
\end{tabular}

وهذا يعني أن هناك فرق دال إحصائياً عندي مستوي (ه ...) بين متوسطي درجات تلاميذ مجموعة البحث في التطبيق البعدي لكل بعُ من أبعاد المقياس ، وفي المقياس ككل لصالح التطبيق البعدي بعد دراسة وحدة "الصوت والضوء" ، وهذا يدل علي أن استخدام بيئة التعلم الافتراضية القائمة على نموذج سوشمان ساهم في تنمية الحس العلمي لاى التلاميذ ، الأمر الذي يقود إلي قبول الفرض الثاني من فروض البحث. ولتحديد مدى تأثثر استخدام بيئة التعلم الافتراضية، تم حساب حجم أثر استخدام بيئة التعلم الافتراضية القائمة على نموذج "سوشمان" للأحداث المتناقضة في تنمية الحس العلمي لاى تلاميذ المجموعة التجريبية، ويوضح جدول (ع ) التالي حجم أثر بيئة التعلم الافتراضية القائمة على نموذج "سوشمان" في تنمية الحس العلمي.

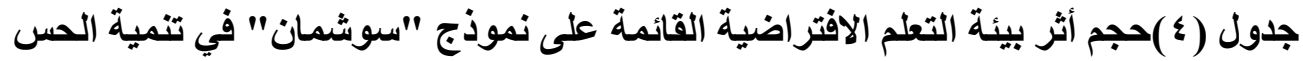

\begin{tabular}{|c|c|c|c|c|}
\hline مستوى الدلالة & حم الأث & م 1. & قيمة "ت" المحسو بة & الأ. عاد \\
\hline مرتفع & 0.79 &.$\wedge 9$ & YY.VT & الاستمتاع \\
\hline مرتفع & $7 . \% 7$ & .91 & $r \leqslant . r V$ & المثابرة \\
\hline مرتفع & $\{.77$ &.$\wedge \theta$ & 11.94 & التمثيل \\
\hline مرتفع & $\{.97$ &.$\wedge 7$ & $19.4 \%$ & الاستدلال \\
\hline مرتفع & $\varepsilon .97$ &.$\wedge 7$ & 19.4. & ادارة وتنظيم الوقت \\
\hline مرتفع & $7 . \vee \wedge$ & .94 & Y . Y & المقياس ككل \\
\hline
\end{tabular}


يتضح من جدول (ء) أن حجم أثر بيئة التعلم الافتراضية القائمة على نموذج "سوشمان" في تنمية الحس العلمي مرتفع في الارجة الكلية للمقياس ومستوياته

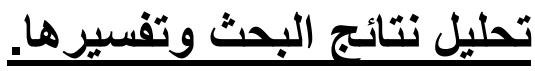
كثفت نتائج اختبار صحة الفرض الثاني عن وجود فرق دال إحصائياً عند مستوي (ه ...)

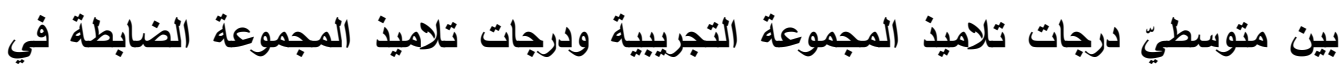
التطبيق البعدي لمقياس الحس العلمي ككل لصالح تلاميذ المجموعة التجريبية، ولما كانت المجموعتان قد درستا وحدة "الصوت والضوء" بعد أن تم ضبط المتفيرات الأخرى بينهما فيما عدا طريقة التدريس المستخدمة ويالتالي فإن التفوق الذى حققته المجموعة التجريبية على التى

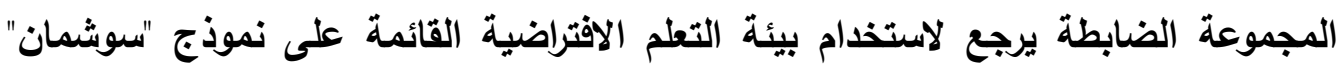
للإحداث المتناقضة في تدريس وحدة "الصوت والضوءع" للمجموعة التجريبية. ويري الباحث أن تفوق المجموعة التجريبية يمكن تفسيره كما يلى: 1- تدريب التلاميذ علي نمط أسئلة مقياس الحس العلمي وخاصة الأسئلة التي تعتمد علي السرعة والتركيز والانتباه ومن ثم لم يجد التلاميذ صعوية تُككر عند تطبيق المفهوم البعدي مقارنة بتلاميذ المجموعة الضابطة. r- طرح عديد من المشكلات العلمية وأثرها علي حياتهم اليومية بالوحدة والتي تتطلب إبداء وجهة النظر واتخاذ موقق حيالها دريّهم علي اتخاذ القرار الصائب والسريع، من خلال التكليفات الموجودة بموقع "تدريس العلوم والحس العلمي". r- تدريب التلاميذ علي التفكير وعمل الخطط ووضع الأهداف وتوسيع معارفهم بتثجيعهن علي البحث عن مصادر للمعرفة غير الكتاب الددرسي ساهم في تنمية العديد من العادئ ممارسات الحس العلمي مثل المثابرة والتنظيم الذاتي والتريث والاستقلالية في التفكير وتقدير ذاتهم.

ع - تعدد التكليفات بالموقع زاد من مثابرتهر على تنفيذ أي تكليف يطلب منهم، وتخطي أي

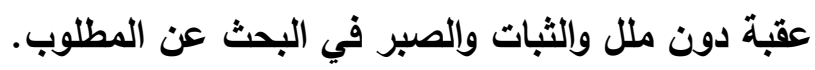
ه- قدرة التلاميذ على تمثيل المعلومات والتعبير عنها بالأشكال البيانية أو من خلال فلاتل تلخيصها باستخام خرائط مفاهيم أو من خلال تمثيلها بأثكال تخطيطية. 
צ- يضم الموقع العديد من الصور والأثكال التخطيطية مما ينمى لدى التلاميذ القدرة على قراءة الصور وتفسيرها وترجمتها من شكل لآخر، مما يدعم أداءاتهم الذهنية وعمليات الانتباه والإدراك.

V يوفر التعلم في موقع (Www.elbaz-sohag.com) خبرات حقيقية لمواقف حياتية يستفيل منها المتعلم في حياته الواقعية خاصة عند حدوث مواقف مشابهة ؛ حيث يمكن مشاهدة لقطات فيديو للأنشطة والمواقف المختلفة، ثم مناقشتها للتعرف علي أهم الآراء ، وكيفية التصرف في حياتتا عند مواجهة مثل هذه المواقف.

$$
\text { توصبات البحث. }
$$

في ضوء النتائج التي توصل إليها البحث الحالي، يوصي الباحث بالاتي:

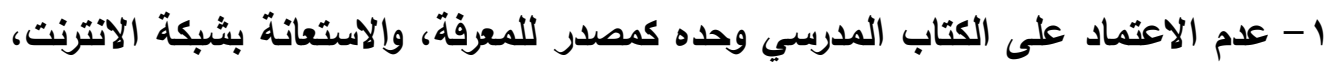
ومواقعها المختلفة في تنمية المفاهيم العلمية. ץ- استخدام البيئات الافتراضية كوسيلة مساعدة في تعليم وتعلم العلوم لما لها من نتائج ايجابية في تتمية المفاهيم العلمية والحس العلمي. r- عقد دورات تدريبية لمعلي العلوم أثثاء الخدمة بهدف إكسابهم مهارات إعداد وإستخدام بيئة التعلم الافتراضية القائمة على نموذج سوشمان للأحداث المتناقضة، لاستخدامها في تلدريس العلوم. ع - تضمين ممارسات الحس العلمى التي توصل إليها البحث الحالى في مناهج العلوم بالمراحل التعليمية المختلفة، بشكل متتابع ومتكامل ومستمر، حسب مستويات ومنطلبات كل صف دراسي. ه- مراجعة أساليب تقويم تلاميذ المرحلة الإعدادية ، بحيث تمثل المفاهيم العلمية ، والحس العلمي جانباً أساسياً فى تقويمهر. 
إبراهيم عبد الله المحيسن (ץ . . ץ): المعلوماتية والتعليم - القواعد والأسس النظرية. الرياض: دار الزمان للنشر والتوزيع.

أحمد بن عبد العزيز المبارك (ع . . †) : أثر التدريس باستخدام الفصول الافتراضية عبر الشبكة

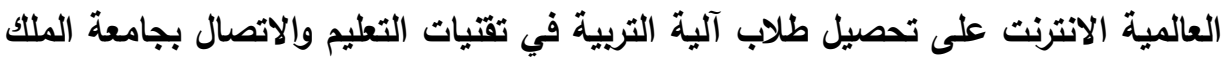
سعود الرياض. رسالة ماجستير . متاح عبر الانترنت. Retrieved from http://www,ksu,edu,sa /sites /KSU Arabic / Deanships /library /Pages/Thesis ,aspx113 (Accessed on :10 /1/ 2015).

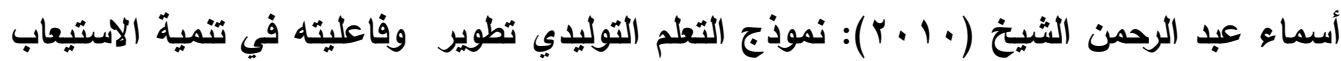

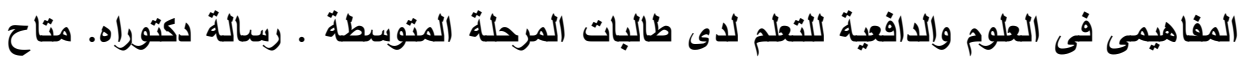

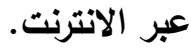

Retrieved from https://faculty.psau.edu.sa/a.alshaikh/ research /rs0000001029 (Accessed on :21/5/2018) اعتماد عواد البلبيسي (؟ . . ץ):أثر استخدام استراتيجية المتناقضات في تعديل التصورات البديلة لبعض المفاهيم العلمية لاى طالبات الصف العاثر الأساسي. رسالة ماجستير كلية التربية،

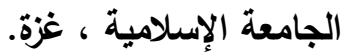

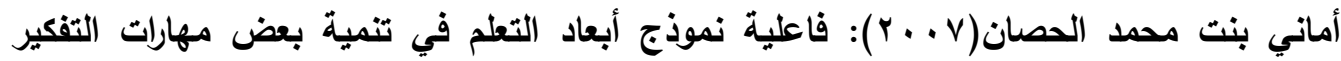

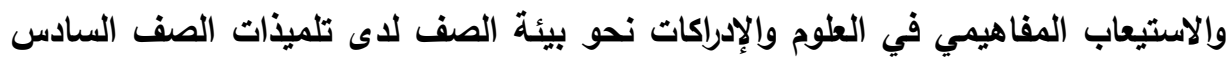

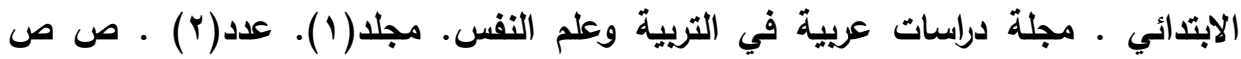
- rro - rlo

Retrieved from https://search.mandumah.com/Record/104406 (Accessed on :27/2/ 2017).

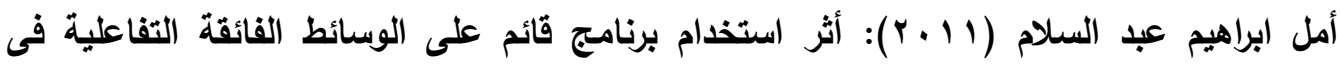
تصويب الأمثلة الخطأ للمفاهيم العلمية وتنمية بعض المهارات الحياتية لتلاميذ الحلقة الثانية

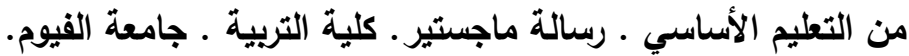

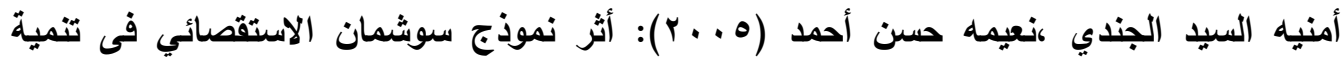

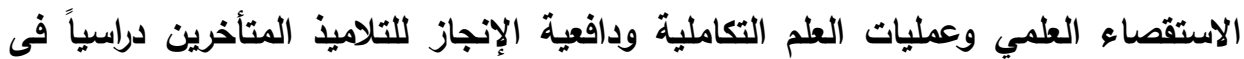
العلوم بالمرحلة الإعدادية ـ مجلة التربية العلمية .الجمعية المصرية للتربية العلمية.

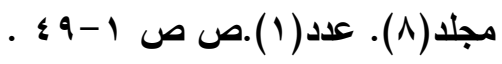


إيمان علي محمود الثحري (11 +r): فعالية برنامج مقترح في العلوم قائم على تكامل بعض

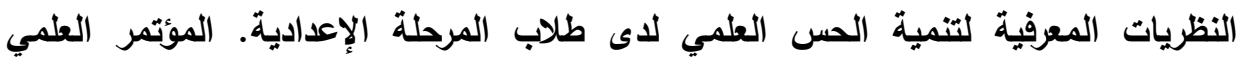

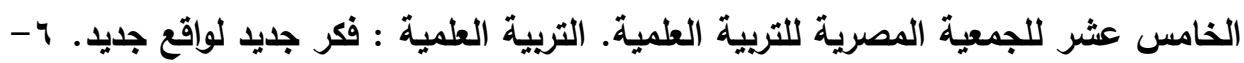

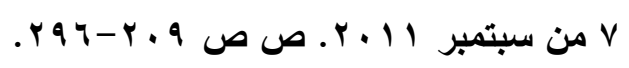

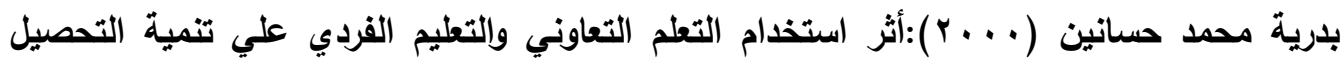

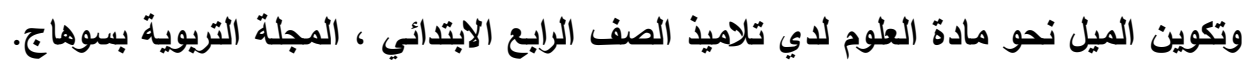

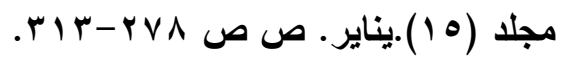

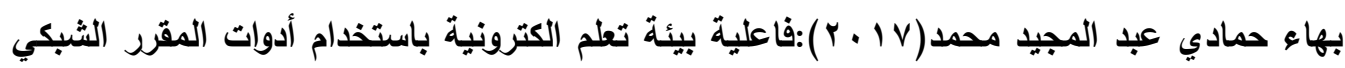
على تنمية المفاهيم العلمية ويعض عادات العقل المنتجة ودافعية الإنجاز لدى تلاميذ الحلقة

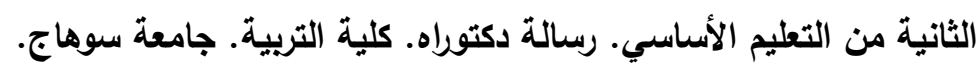

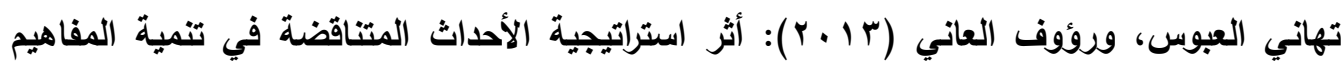

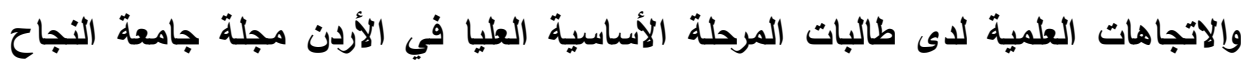

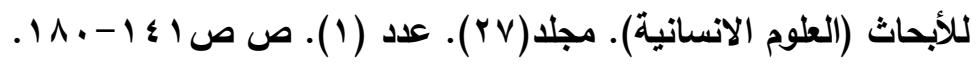

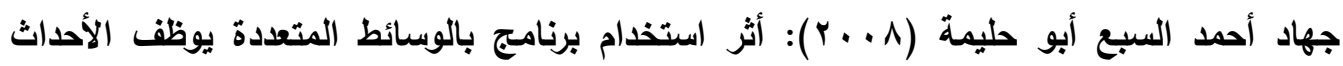

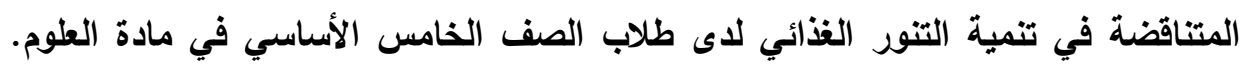

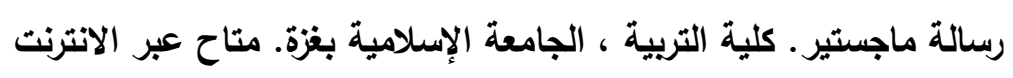

Retrieved from http://search.mandumah.com/Record/541769 (Accessed

$$
\text { on :17/2/ 2018). }
$$

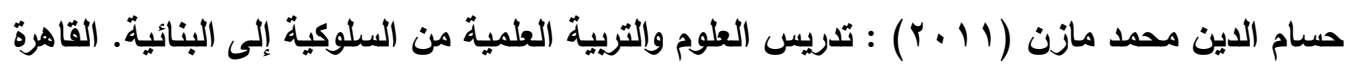

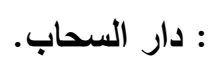

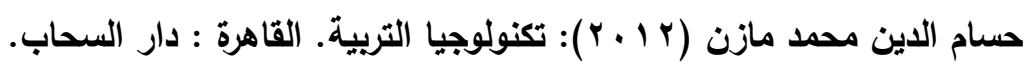

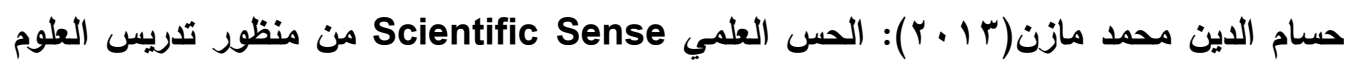

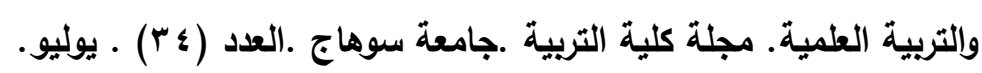

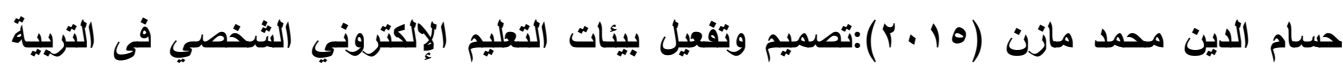

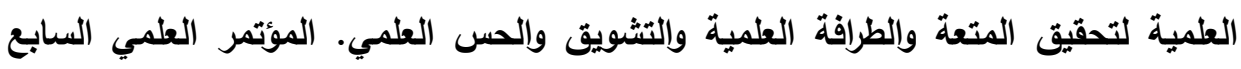

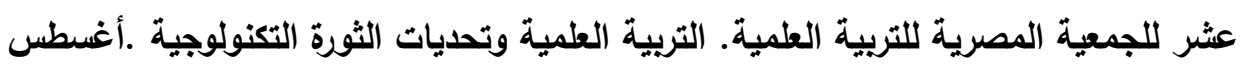

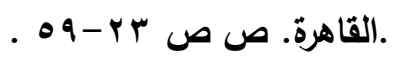

http://search.mandumah.com/Record/703028

(Accessed on :18/2/ 


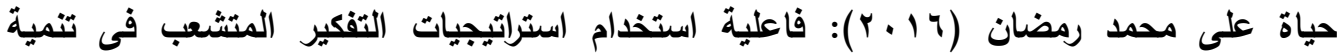
التحصيل والحس العلمي وانتقال أثر التعلم فى مادة العلوم لاى تلاميذ المرحلة الابتدائية.

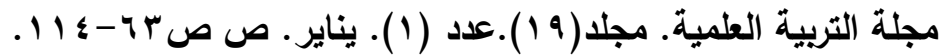

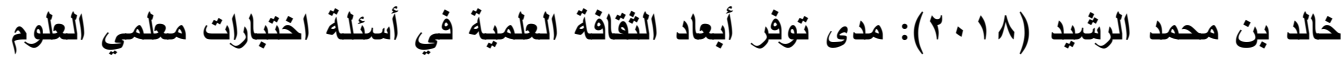
للصف الأول الثانوي وعلاقته بمتغير الجنس والتخصص. مجلة التربية العلمية.

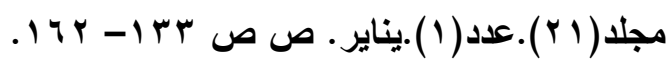

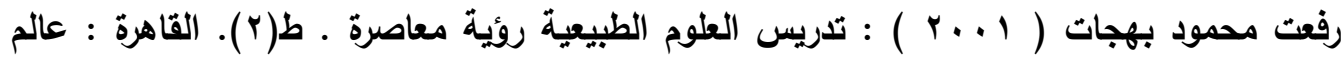

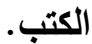

سالي كمال ابراهيم عبد الفتاح (Y ( + Y): برنامج مقترح لمعلمي العلوم قائم علي مدخل المعلم كعالم لتنمية الحس العلمي ويعض متطلبات الكفاعة المهنية لديهم. رسالة دكتوراه ـ كلية التربية.

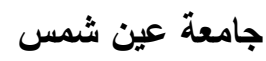
سعود بن حسين الزهراني (؟ . . †)، "تطوير استراتيجيات تدريس التاريخ في التعليم العام: مشروع

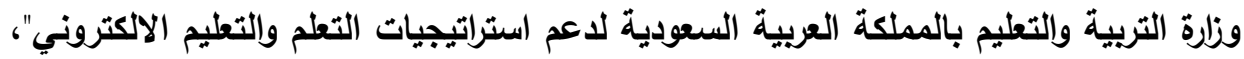

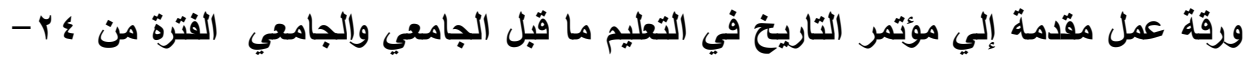

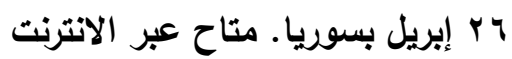
Retrieved from http:// dr-saudalzahrani. Com. /pages. Php ? pid =113 (Accessed on :17/9/2017).

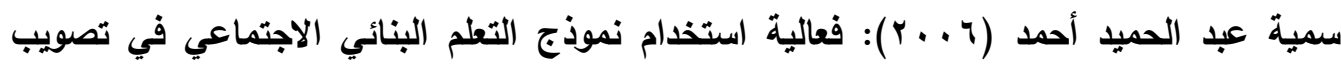

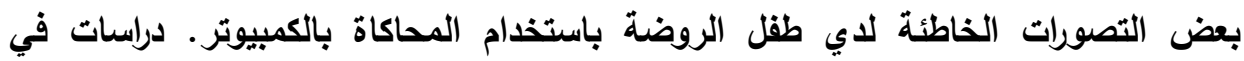

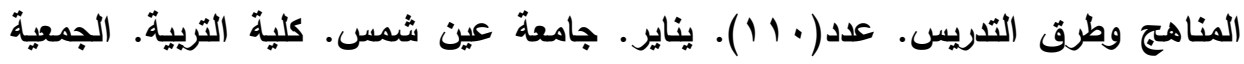

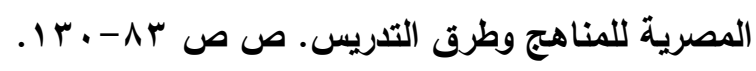

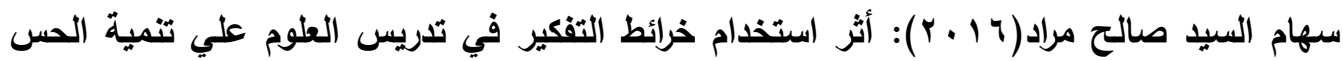

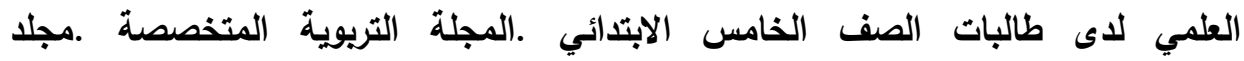

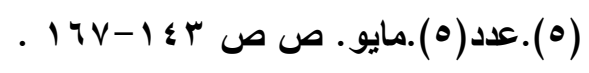

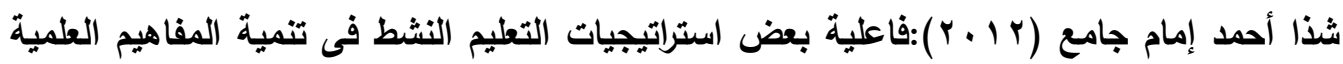
والاتجاه نحو مادة العلوم لاى تلاميذ المرحلة الإعدادية بالمدارس التجريبية ـ رسالة ماجستير . كلية التربية. جامعة حلوان. 


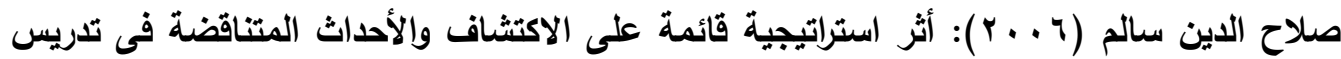
العلوم على تنمية التحصيل وعمليات العلم والتفكير الابتكاري لدى الصف السادس بالتهلئ التعليم

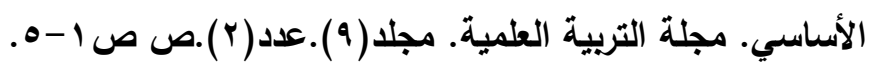

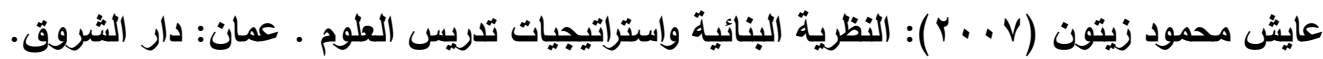
عبد السلام مصطفى عبد السلام (1 +. r): الاتجاهات الحديثة في تدريس العلوم. القاهرة: دار الفكر

$$
\text { العربي. }
$$

عبد السلام مصطفي عبد السلام (9 . . ץ):تدريس العلوم وإعداد المعلم وتكامل النظرية والممارسة . القاهزة : دار الفكر العربي.

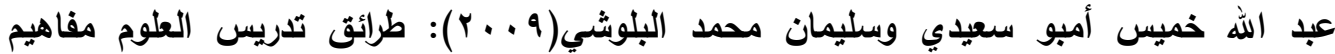

$$
\text { وتطبيقات عملية. عمان: دار المسيرة. }
$$

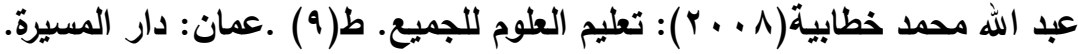

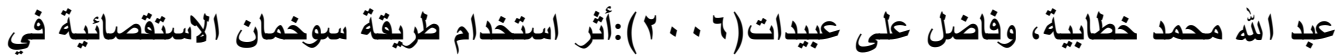
التحصيل الآني والمؤجل في مادة العلوم لطلبة الصف السابع الأساسي .مجلة دراسات العلوم

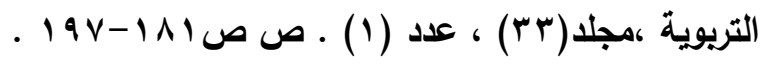

على زهدي شقور ( ؟ . . ץ ) :" البيئة الافتراضية والتعليم " متاح عبر الانترنت

Retrieved from http:// www.moufoud.jeeran.com/archive / 2006

19/99104 .html. (Accessed on 10/2/2016).

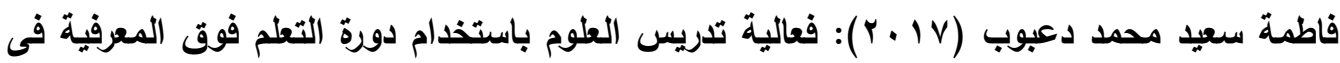
اكتساب المفاهيم العلمية وتنمية مهارات التفكير الناقد لاى طالبات الصف الثالث المتوسط.

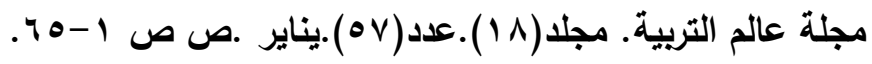

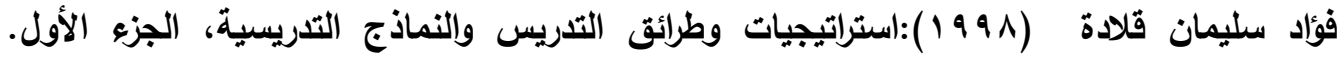
القاهرة: دار المعرفة الجامعية. كريمة عبد اللاه محمود(Y P V V):وحدة مقترحة فى العلوم قائمة على التعليم المتمايز لإكساب المفاهيم العلمية والحس العلمي لتلاميذ الصف الثاني الابتدائي. مجلة التربية العلمية. مجلا

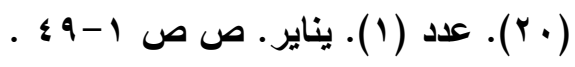

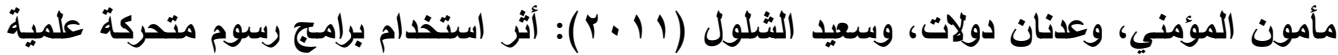
فى تدريس العلوم فى اكتساب التلاميذ للمفاهيم العلمية. دراسة تجريبية على تلاميذ الصف

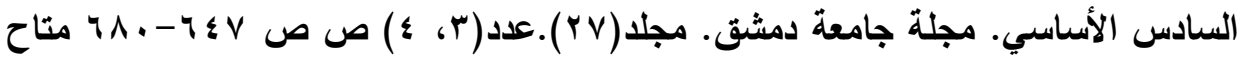


Retrieved from http://www Damascus university -sy/mag /edu /images /647-680.pdf (Accessed on :25/10/ 2017) محمد السيد(ه . . r): تكنولوجيا التعليم والوسائل التعليمية .طنطا: مكتبة الإسراء.

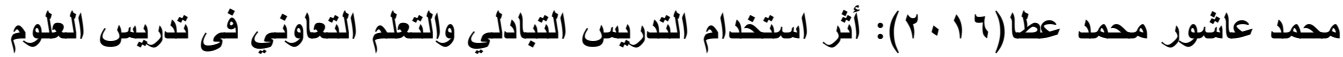
على اكتساب المفاهيم العلمية وتتمية مهارات التفكير الناقد لاى تلاميذ الصف الثاني الإعدادي. رسالة دكتوراه. كلية التربية. جامعة المنيا. المركز الوطني للتعلم الإكتروني والتعليم عن بعد : (ب ب ب) المؤتمر الدولي الثالث للتعلم الاكتروني والتعليم عن بُعد ، تحت شعار" الممارسة والأداء المنشود" خلال الفترة من بَr - צب ربيع

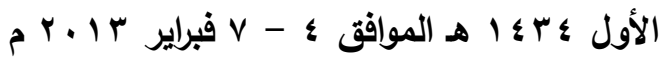

Retrieved from :http://www.elc.edu.sa/portal/index.php?mod= news \&

$$
\text { page =3\&annID=977 (Accessed on:10/ 2/2013). }
$$

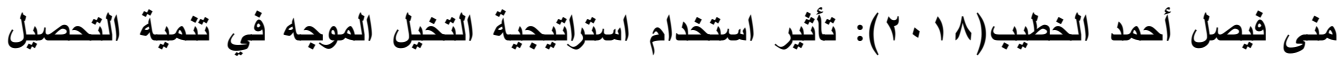
ومهارات حل المشكلات البيئية والحس العلمي لاى طالبات كلية البنات ـ مجلة التربية العلمية

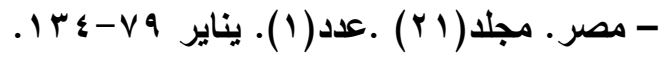

مهدي محمد جواد (10 + ب): فاعلية استراتيجية الأحداث المتناقضة في التحصيل وتتمية التفكير الناقد لاى طلاب الصف الرابع العلمي في مادة الفيزياء ـ مجلة كلية التربية الأساسية للعوم

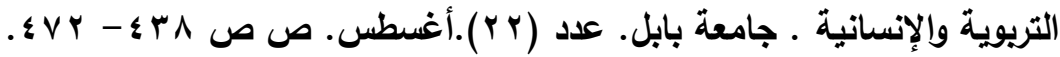
نبيل جاد عزمي (؟ 1 + †): بيئات التعلم التفاعلية ـ دار الفكر العربي ـ القاهرة .

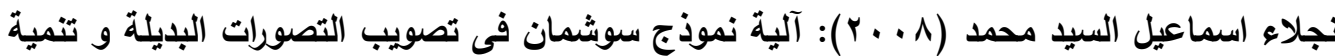
مهارات الاستقصاء العلمي لدى تلاميذ المرحلة الاعدادية ـ رسالة ماجستير. كلية البنات .

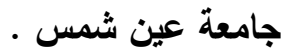
نجلاء حسين عبد القوى (11 + ب): فاعلية برمجية كمبيوتر تعليمية معدة في ضوء التكامل بين العلوم والتكنولوجيا في اكتساب المفاهيم العلمية وتنمية التنور العلمي والتكنولوجي لاى تلاميذ الصف الأول الإعدادي رسالة ماجستير ـ كلية التربية. جامعة المنيا.

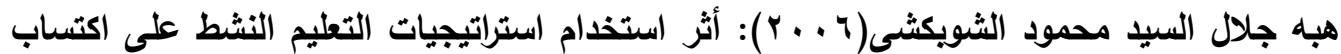

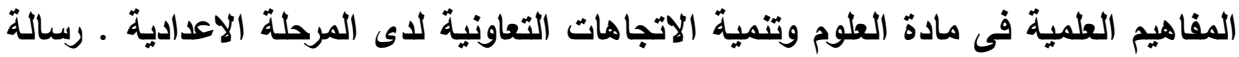
ماجستير . كلية التربية . جامعة الزقازيق. 


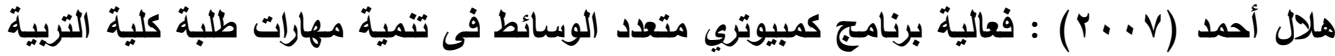

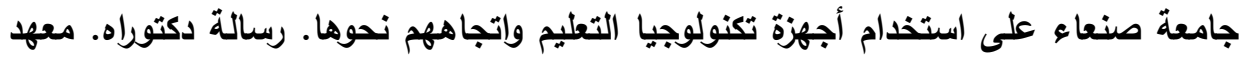
الداسات والبحوث التربوية. جامعة القاهرة.

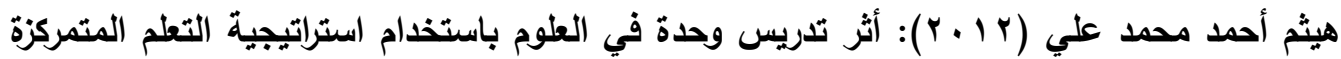
حول المشكلات لتلاميذ الصف الأول الإعدادي في تنمية المفاهيم العلمية والتفكير العلمي لهي لايهم. رسالة ماجستير · كلية التربية. جامعة المنيا.

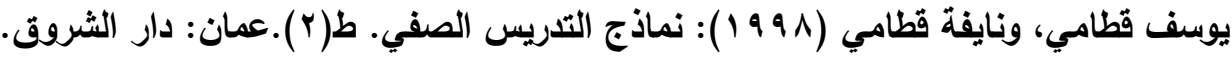

Ash, D. (2003): Dialogic inquiry in life Science conversations of family groups in a measure. Journal of Research in Science Teaching . Vol (40). No (2).Pp 138-162

Ash D. (2004): Reflective scientific sense making dialogue in two language: The Science in dialogue and Dialogue in the Science. Science Education . Vol (88). No (6).Pp 855-884.

Ash, D. (2009):Shared scientific sense- making and bilingual student advancement in Science :lining family and School learning through informal learning research - informal learning, University of California -Santa Cruz.

Bulunuz , N. and Olga. Jarrett .(2010). The Effects of Hands on Learning Science Stations on Building American Elementary Teachers Understanding about Earth and Space Science Concepts. Journal of Mathematics Science and Technology Education .Vol (6). No(2). .Pp 85-99.

Chang, C. Y., Yeh, T. K., \&Barufaldi, J. P. (2010).The positive and negative effects of science concept tests on student conceptual understanding. International Journal of Science Education. Vol .(32). No.(2). Pp 265-282. Retrieved From: ERIC :EJ816397. (Accessed on :8/ 10 / 2017).

David, P., (2013): Sense about science making sense of uncertainty; why uncertainty is a part of science, London . Retrieved From ERIC .No. 1146/70 .(Accessed on :11/ 9 / 2016).

Elaine, M. (2009): the benefits of sustained silent reading: Scientific research and common sense converge, Journal of Science Education and Technology. Vol. (62). No. (4).Pp 336 - 344.

Heller, J. \& Joan, I. (2012): Effect of Making sense of science professional development on the achievement of middle school students including English language learners. Science Education .Vol. (50) . No (8).

Laura, Z. \& Cory, Forbes \& Mandy, Biggers (2013) : Fostering Student Sense making in elementary science learning environments : 
Elementary teachers' use of Science Curriculum materials to promote explanation construction. Journal of Research in Science Teaching . Vol. (50). No.(8). Pp.989-1017 .

Liu, C - (2005): Web-based Cognitive Apprenticeship Model for Improving Pre-service Teachers. Performances and Attitudes Towards Instructional Planning Design and Experiment. Education Technology \& Society. Vol. (8). No. (2). Pp136-149. Retrieved from : ERIC (EJ844723) (Accessed on 10/6/2017).

Molotsky , Gregg Jeremy (2011): A Case Study of the Impact of a Reformed Science Curriculum on Student Attitudes and Learning in a Secondary Physics Classroom. Retrieved from: ERIC (ED 530666) (Accessed on 10/11/2016).

Newman, D.. et al. (1993): The conflict between teaching and scientific sense- making: The case of a Curriculum on Seasonal change. Interactive Learning Environments. Vol. (3). No. (1). Pp. 1-15. Retrieved from: ERIC (EJ479865). (Accessed on 10/6/2018).

Short, Daniel. (2012): Teaching Scientific Concepts Using a Virtual World--Mine craft. v58 n3 pp55-58.Retrieved from: ERIC (EJ9912956). (Accessed on 15/8/2016).

Wilson, J. González \&.Jennifer Birriel \& Ignacio Birriel.(2010): "Discrepant Events: A Challenge to Students' Intuition. The Physics Teacher. Vol (48).No(8).Pp508-511 Nov .Retrieved from ERIC: EJ912883. (Accessed on 25/12/2017). 